الهيئة العامة للتعليم التطبيقي والتدريب

كلية التربية الأسـاسية

قسم الدراسـات لإسلامية

\title{
القول المستطاب
}

\section{في مصطلح الاضطراب}

$$
\text { اسم الباحثين }
$$

د. إبر اهيم محمد محمد عبد العال الحناوي

أستاذ الحديث - جامعة الأزهر الشريف-

د.محمد يوسف الشطي

أستاذ مشارك بكلية التربية الأساسية 
$-\wedge \Lambda Y-$ 


$$
\text { بسم اللَّ الرحمن الرحيم }
$$

\section{المقدمة}

الحمد لله الفتاح المنان، ذي الطول والفضل والإحسان، الذي من

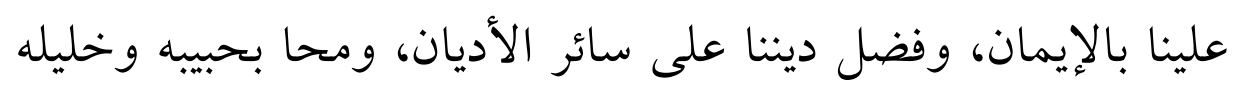

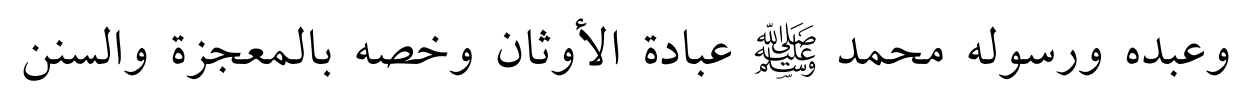

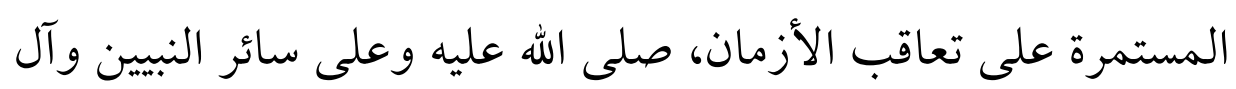

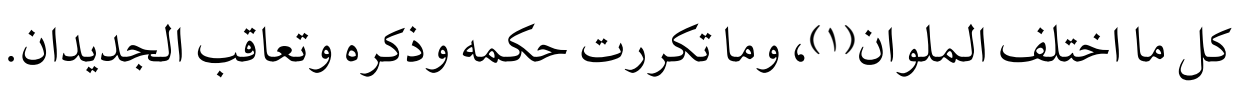

$$
\text { أما بعد: }
$$

فإن الاشتغال بالحديث وعلومه وتحصيله، و التصنيف فيه، خير ما

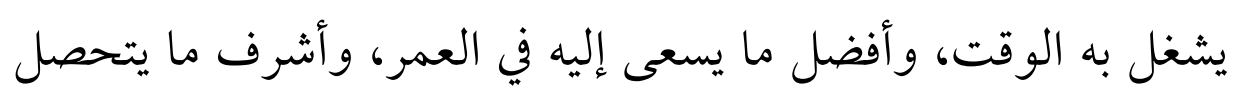

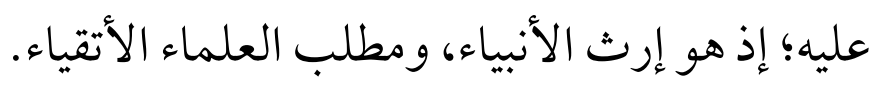
وكذلك أفهام حملة العلم من السنن والآثار متفرقة وإراداتهم متفاوتة وهممهم إلى التباين مصروفة وطبقاتهم فيما حملوه غير التهن

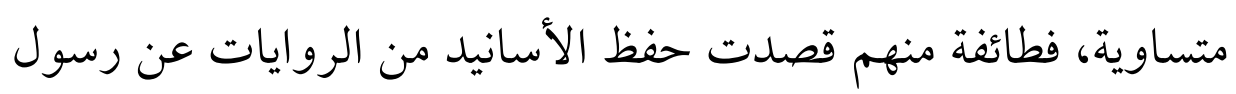

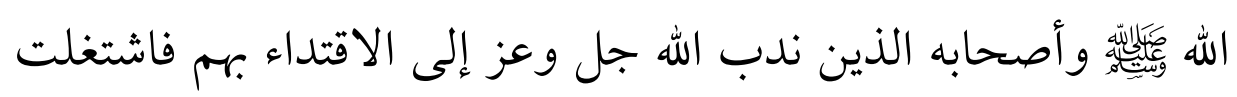

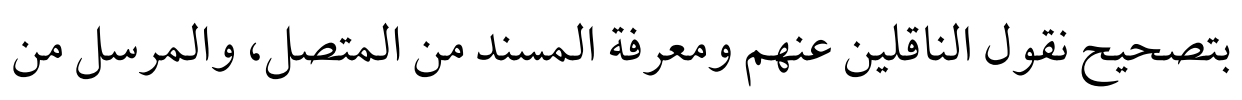

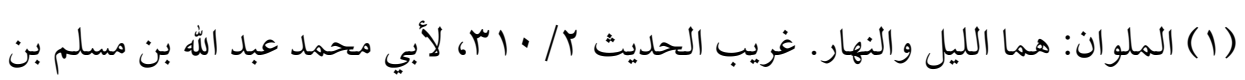

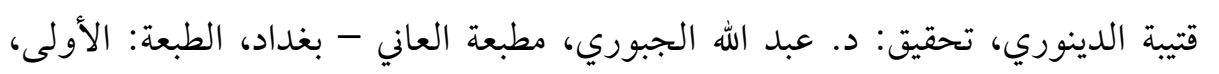


المنقطع، والثابت من المعلول، والعدل من المجروح؛ فهؤلاء حفاظ

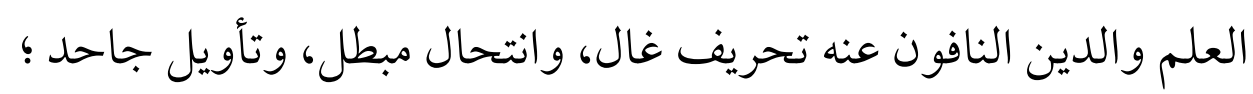

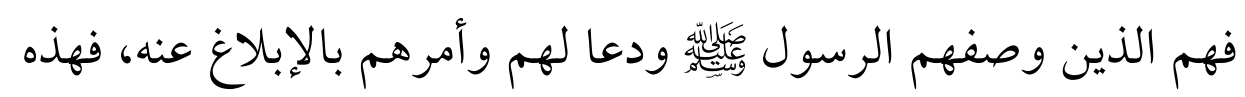

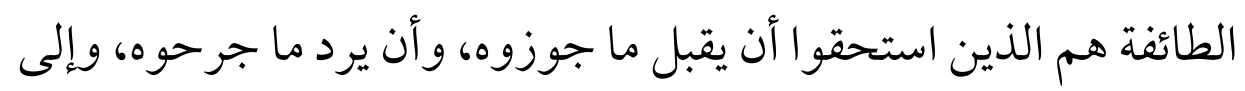
قولهم يرجع عند التدليس أو التحريف أو التأويل المبطل.

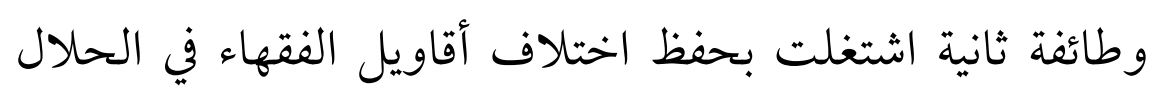

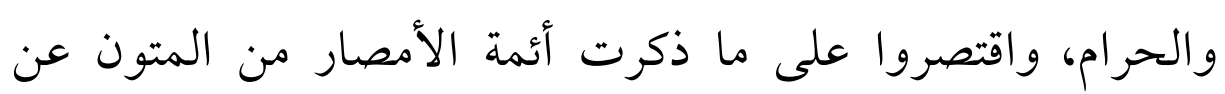

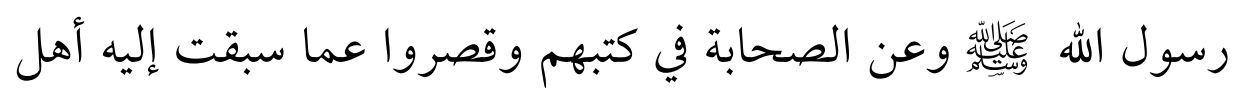

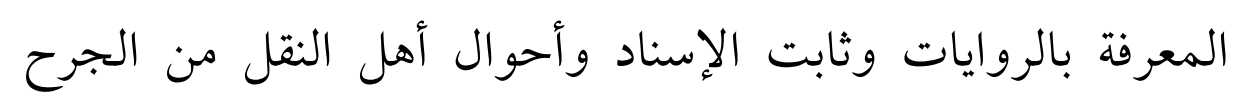

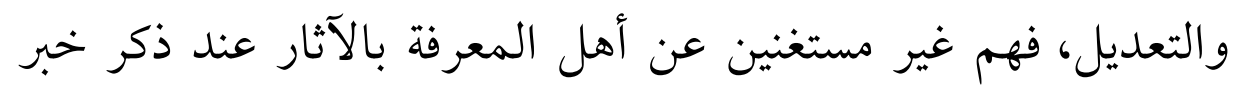

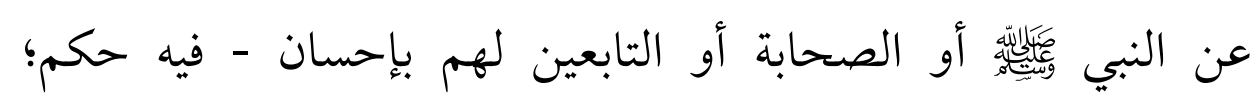
ليعرفوا صحة ذلك من سقمه وصوابه من خطئه.

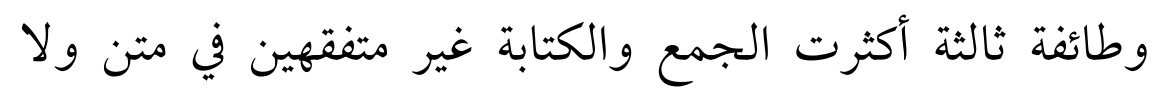

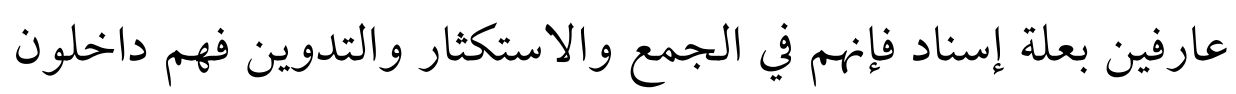

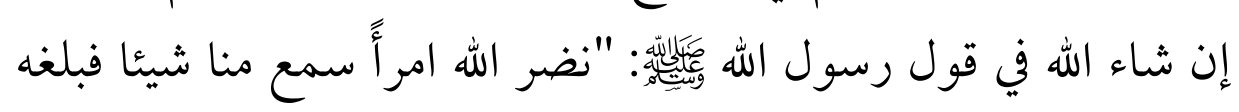

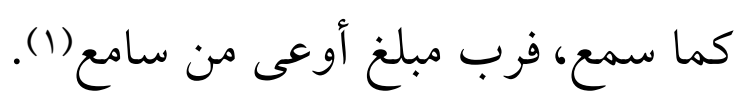

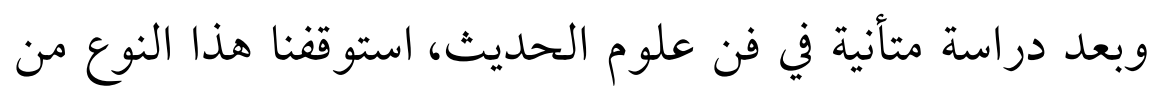

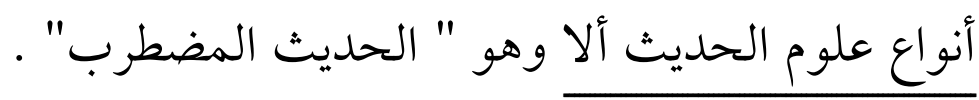

$$
\begin{aligned}
& \text { (1) أخرجه الترمذي في سنه - رقمr (Y) ) - )، وقال الترمذي حسن صحيح. }
\end{aligned}
$$


ولصعوبة هذا النوع وكثرة اختلاف الأئمة فيه سمينا هذا البحث

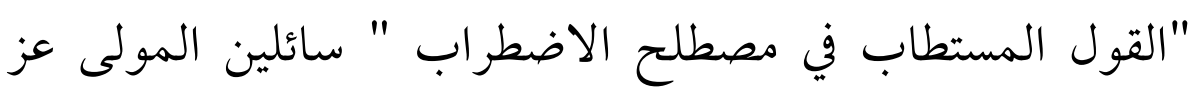

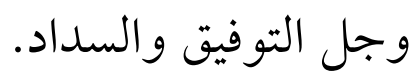

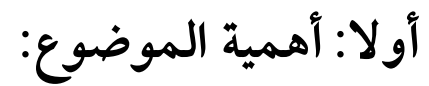

وتتجلى أهمية الموضوع فيما يلي: المديه الموضو:

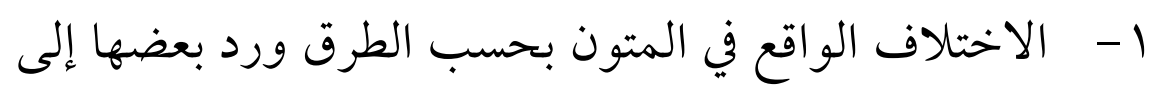

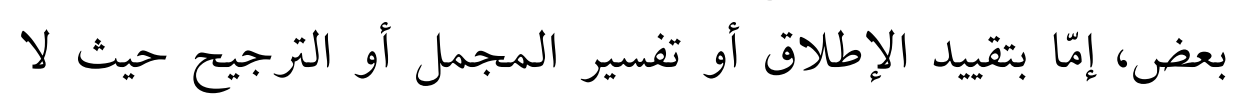

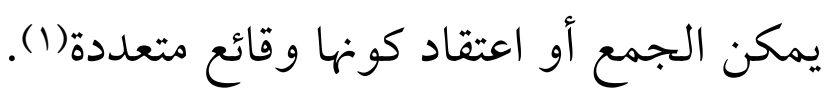

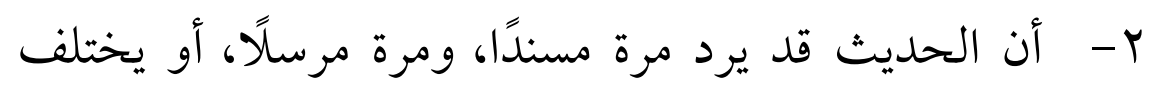

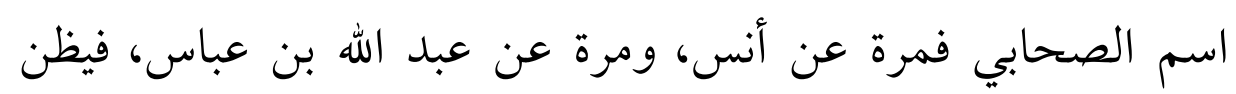

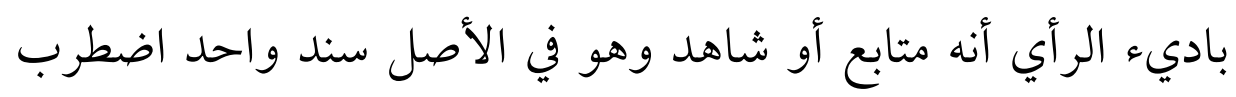

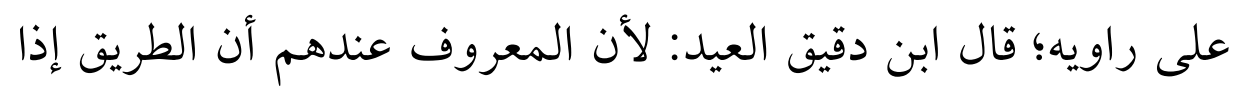

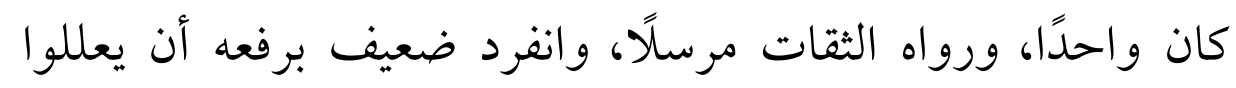
المسند بالمرسل ويحملوا الغلط على رواية الضعيف(r).

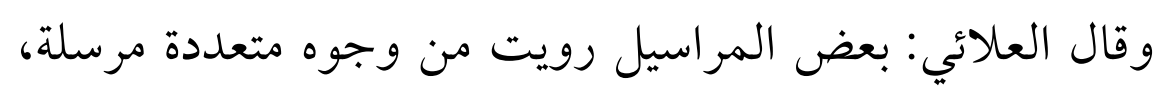

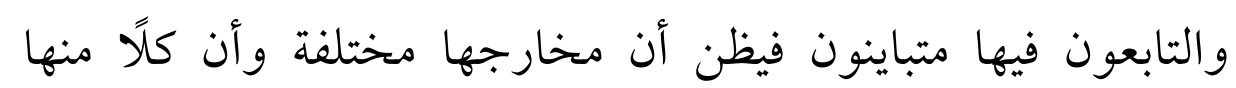

(1) نظم الفر ائد لما تضمنه حديث ذي اليدين من الفوائد / / / 1 ا ، العلائي .تحقيق: بدر البدر.

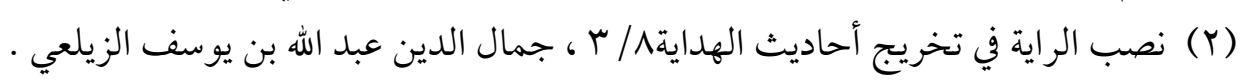
تحقيق: أعضاء المجلس العلمي بدابهيل - الهند. 
يعتضد بالآخر ثم عند التفتيش يكون مخرجها واحدًا ويرجع كلها

$$
\text { إلى مرسل واحد(1). }
$$

r- أنه يدرس الأحاديث مبينًا طرقه واختلاف الرواة فيه.

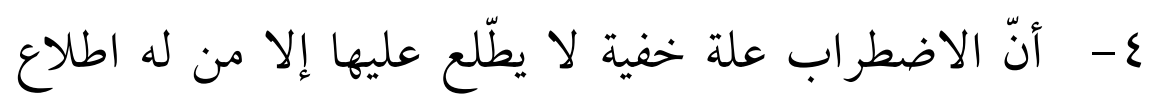

$$
\text { بطرق الحديث مع الخبرة والفهم الثاقب. }
$$

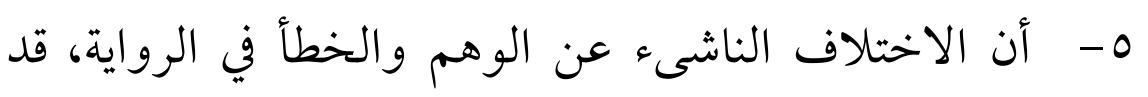

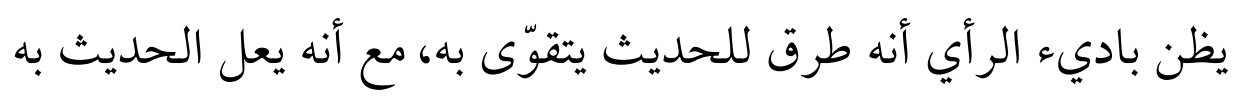

في حقيقة الأمر.

7 - ومن أهميته أن الرواة قد يضطربون في الاسم في السند أو

في المتن فمن خلال دراسة الحديث قد نستطيع بيان الراجح في فئه

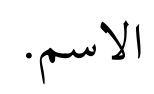

- V ومن أهميته معرفة صحة الحديث من سقمه.

$$
\text { ثانيا: أسباب اختيار الموضوع: }
$$

- - من أهم أسباب اختيار هذا الموضوع دقته إذ يتعلق بأمرين:

$$
\text { أ - بعلم العلل، ب - بعلم الجرح والتعديل. }
$$

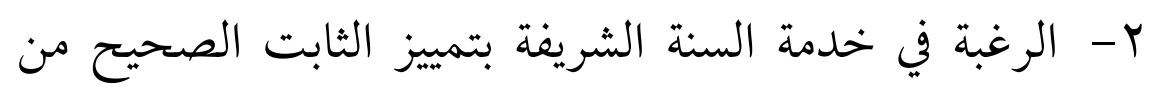

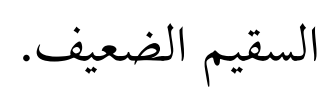

(1) جامع التحصيل في أحكام المراسيل 0؛ ، صلاح الدين أبي سعيد خليل بن كيكلدي

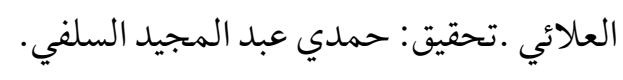


ب- محاولة جمع ما يتعلق بهذا الموضوع في مكان واحد بحيث يسهل مأخذه ويقرب على طالبه.

ع - الاستفادة من تصرفات الأئمة والحفاظ في الأحاديث المعلة

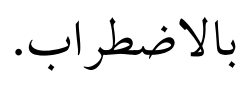

0- معرفة الاختلاف المؤثر في ثبوت الحديث من الاختلاف لاف

$$
\text { الذي لا يؤثر فيه. }
$$

ج- ترك الإنكار والتشدد بين المسلمين إذا عُلم أن الحديث

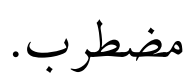

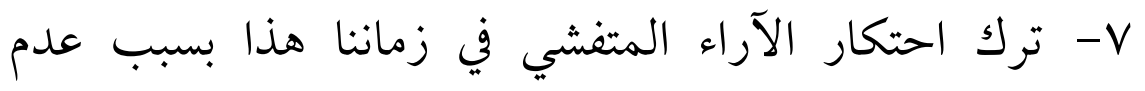

$$
\text { الوقوف على معيار معين في ضبط أحد الترجيحات. }
$$

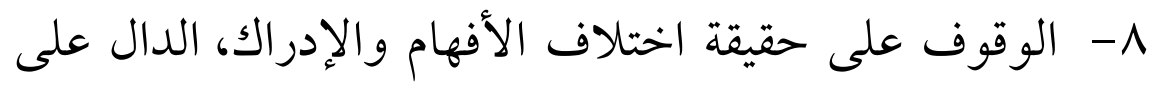

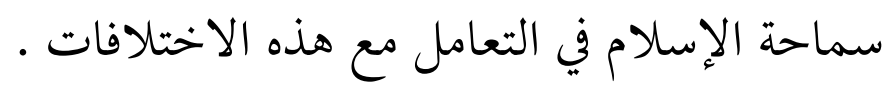

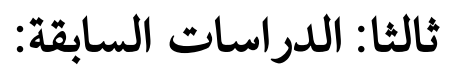

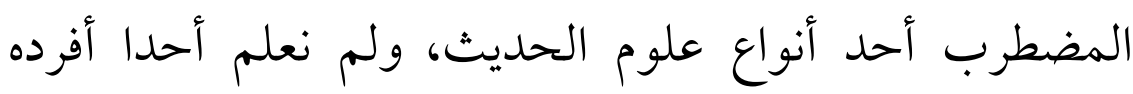
بالتصنيف إلا كتاب للحافظ ابن حجر بعنوان " المقترب في بيان المبان

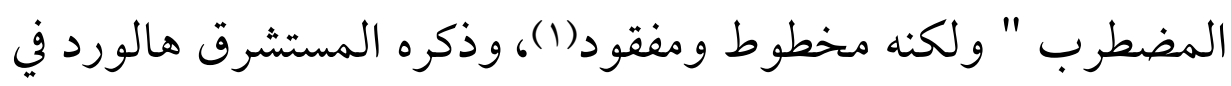

(1) ابن حجر العسقلاني مصنفاته ودراسة في منهجه ومو ارده في كتابه الإصابةه • ب/ 1 ، شاكر 
فهرسته لمكتبة برلين رقم اع 1 ال فالله أعلم(1). وأخذ هذه التسمية - المقترب في بيان المضطرب رفين - الباحث: أحمد بن عمر بن سالم بن أحمد بن عبود أبو عمر بازمول السلفي

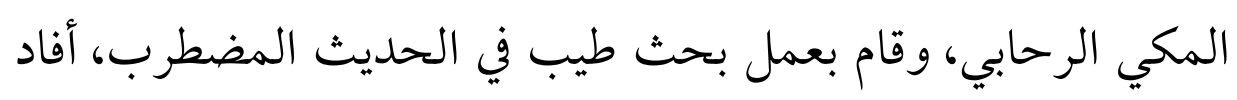
فيه وأجاد، وقد استفدنا منه كثير ا.

وهناك مؤلفات مشتركة ضمن علوم الحديث، وهي عبارة عن وني

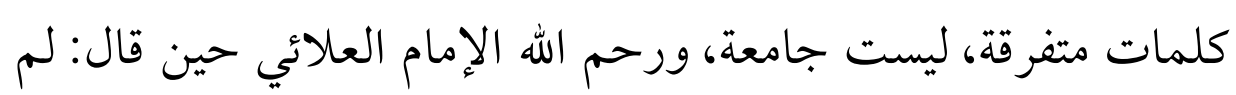

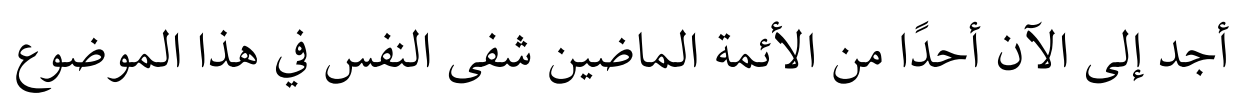

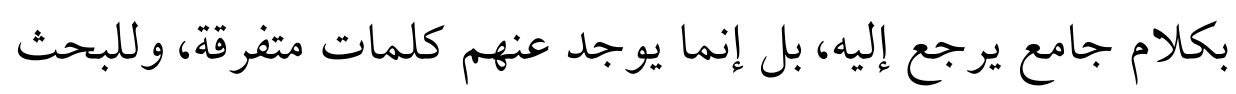
فيها مجال طويل (r). ومن هذه المصنفات الحديثية التي تكلمت عن هذا المصطلح: علوم الحديث لابن الصلاح، والاقتراح في بيان الاصطلاح لابن دقيق العيد، النكت على ابن الصلاح لابن حجر، والزركشي وغيرها، وكتب العلل وهي كثيرة.

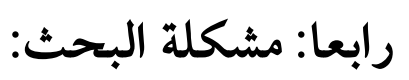

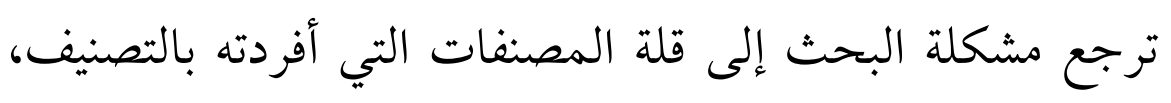

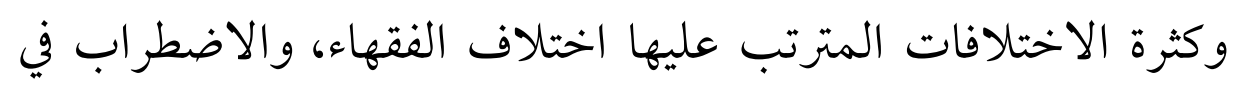
(1) (1) صبحي السامر ائي في تحقيقه للخلاصة في أصول الحديث للطيبي(Vr) (V) حاشية رقم (1) .

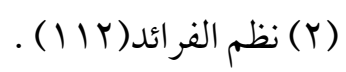


وصف الثقة بقلة الضبط، وتضعيف كثير من الروايات بسبب عدم

$$
\text { الوقوف على مرجح. }
$$

خامسا: خطة البحث:

قسمنا البحث إلى تمهيد وأربعة فصول وخاتمة.

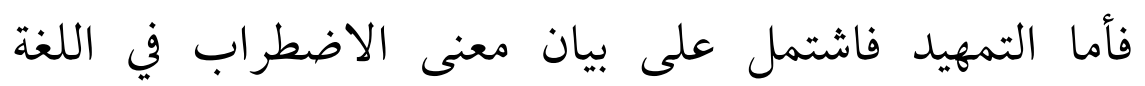

والاصطلاح، والشروط التي يصير بها الحديث مضطربا.

وأما الفصل الأول: أنواع الاضطراب ولئ وفيه ثلاثة مباحث.

المبحث الأول: مضطرب السند وفيه مطلبان:

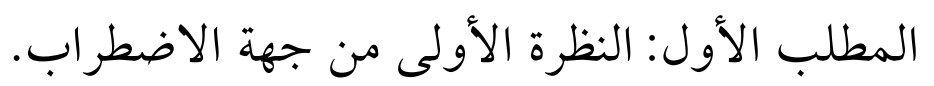

المطلب الثاني: النظرة الثانية: من جهة الراوي. وفيه أربعة الربعة مسائل.

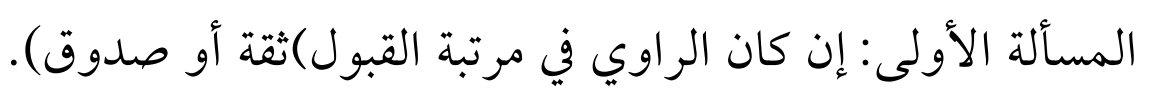

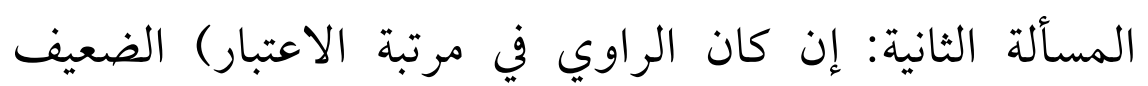

المنجبر)

المسألة الثالثة: إن كان الراوي في مرتبة الترك) الضعيف الذي لا

مينجبر)

المسألة الرابعة: بيان ما يقبل التقوي.

$$
\text { المبحث الثاني: مضطرب المتن. }
$$

المبحث الثالث: مضطرب السند و المتن.

الفصل الثاني: آراء العلماء في الاختلاف على على الراوي. وفيند والثتن خمسة 
مباحث.

المبحث الأول: المذهب الأول: الاختلاف يؤثر مطلقا إلا إن دل

دليل.

المبحث الثاني: المذهب الثاني: الاختلاف في السند لا يؤثر وقد

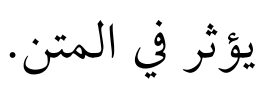

المبحث الثالث: ليس كل اختلاف مؤثرا.

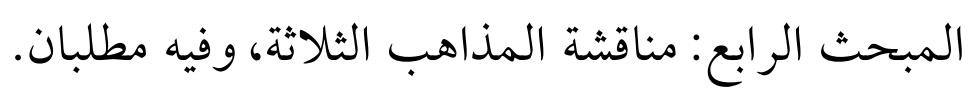

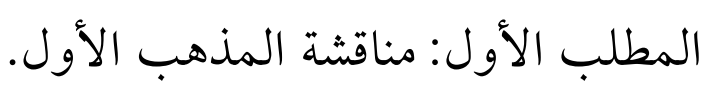

المطلب الثاني: مناقشة المذهب الثانئ المدهب الاول.

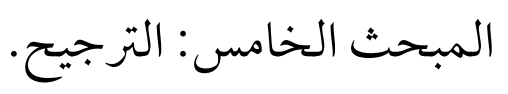

الفصل الثالث: أثر الاضطر ابت على السند والمتن. وفيه مبحثان.

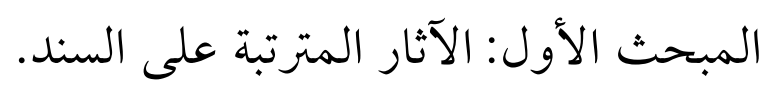

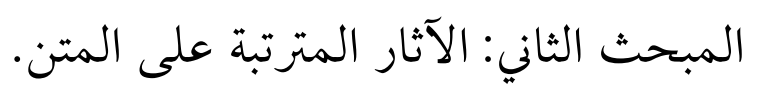

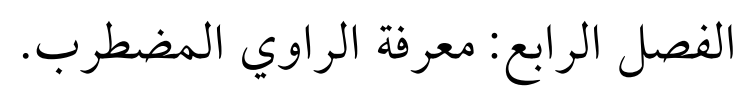

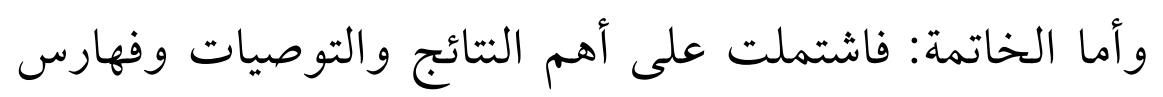

علمية.

سادسا: منهج البحث.

سلكنا في هذا البحث المنهج الاستقرائي الموضوعي وفقا

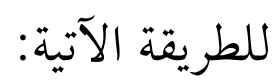

$-\wedge 9 \cdot-$ 
توثيق المادة العلمية.

r - خرجنا الأحاديث بعزوها إلى مخرجيها، مع الاكتفاء

بالعزو إلى الصحيحين أو أحدهما.

r- قمنا بعزو الأقوال إلى قائليها بالأصل أو أو بالإحالة.

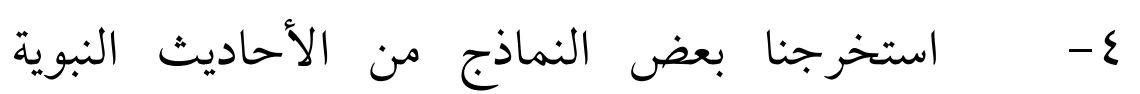

للاسترشاد به كنماذج للأحاديث المضطربة.

- - م:منا بعمل فهارس علمية للمصادر والمراجع

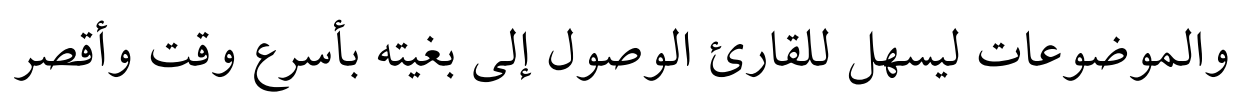

طريق.

سائلين الله العلي القدير أن يتقبل منا هذا العمل، وأن يبارك لنا

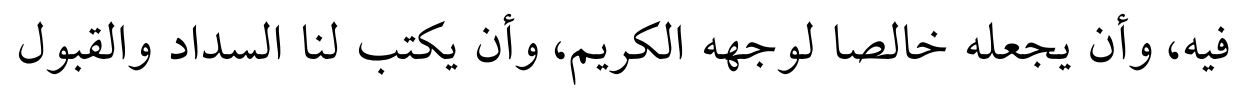

والتوفيق.

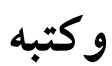

د.إبراهيم محمد محمد الحناوي

د.محمد يوسف الشطي 


\section{التمهيد:}

كان لزاما قبل الشروع في ذكر أقوال المحدثين في الحديث المضطرب وتقسيم هذا البحث تقسيما علميا، أن نبين معنى الاضطراب في اللغة والاصطلاح.

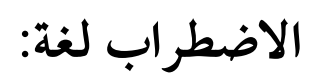

أصل كلمة) اضطرب (ضرب .ومادة الضاد والراء والباء أصل

$$
\text { واحد ثم يستعار ويحمل عليه(1). }
$$

وكلمة الاضطراب تدل على حركة وعدم ثبات الشيء واختلاله وعدم انضباطه يقال: اضطرب الحبل بين القوم إذا اختلفت كلمتهم

$$
\begin{aligned}
& \text { و اضطرب أمره اختل واضطرب تحرك وماج(r). } \\
& \text { المضطرب اصطلاححًا: }
\end{aligned}
$$

قال ابن الصلاح: المضطرب من الحديث هو الذي تختلف

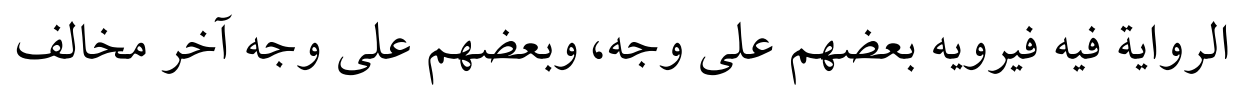

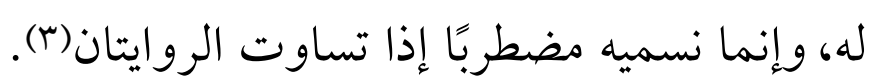

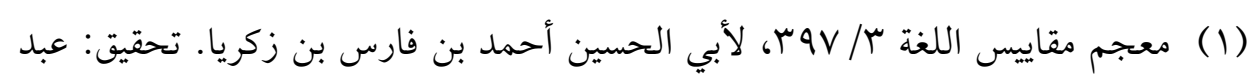

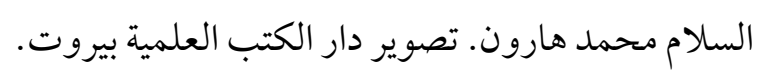

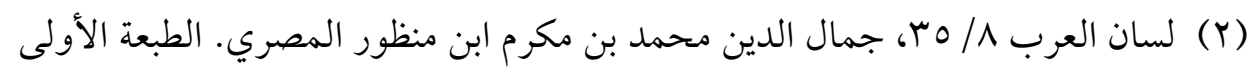

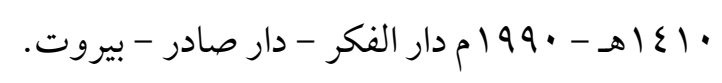

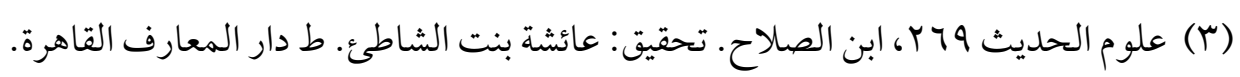


وقيل: هو الحديث المروي على أوجه مختلفة مؤثرة متساوية في

$$
\text { القوة ولا مرجح (1). }
$$

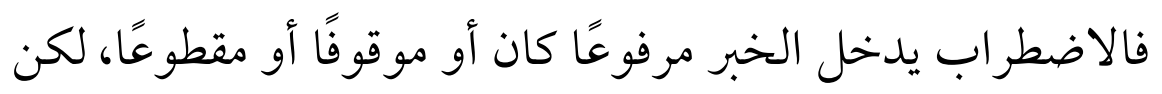

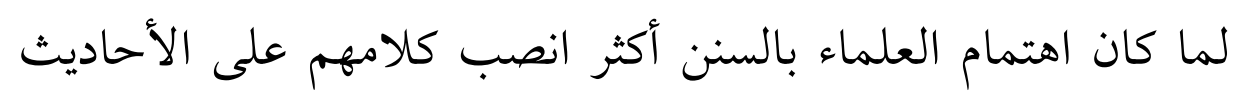

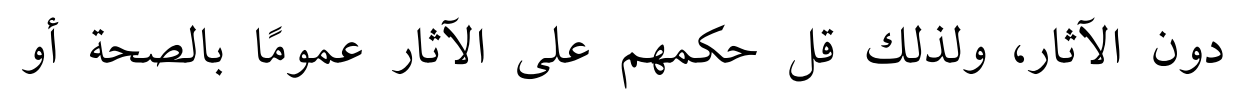

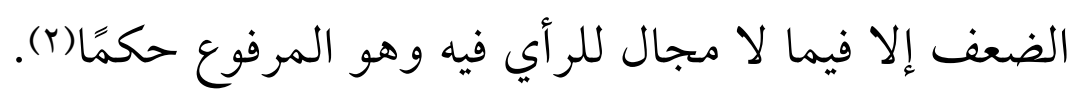

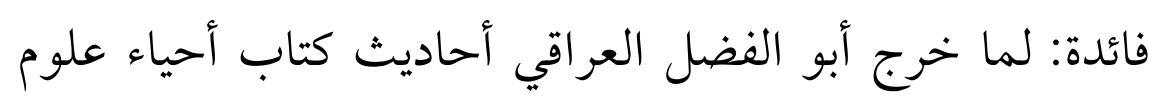

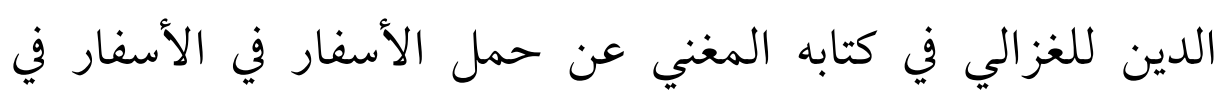

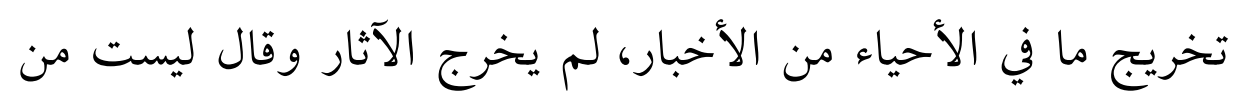
شر طه(r).

وقال ابن رجب: إذا علم أن الحديث الذي اختلف في إسناده

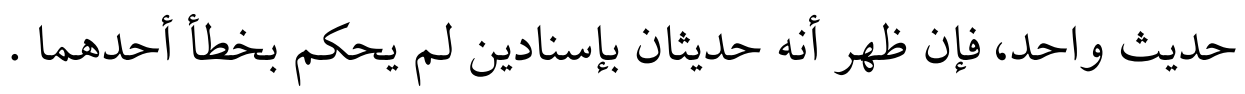

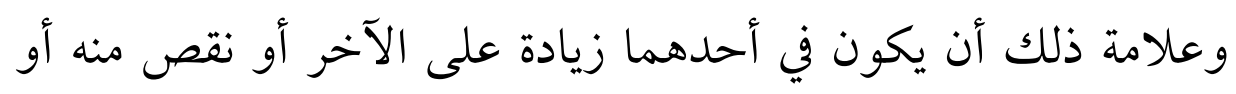

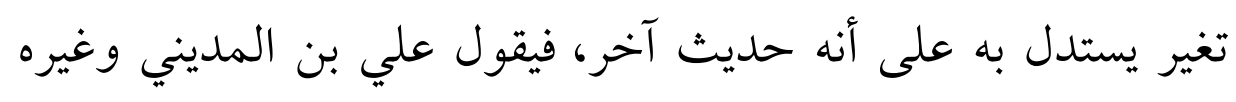

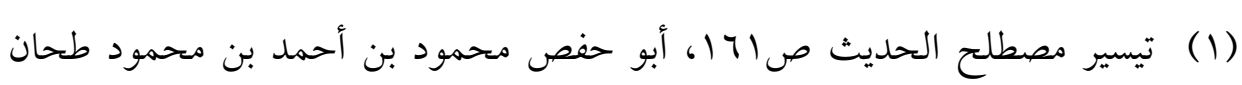

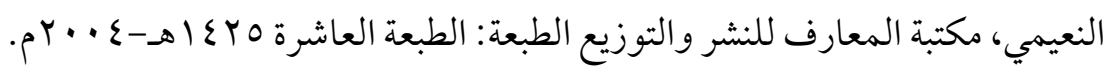

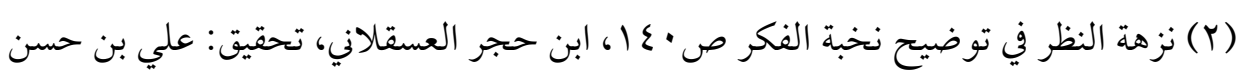

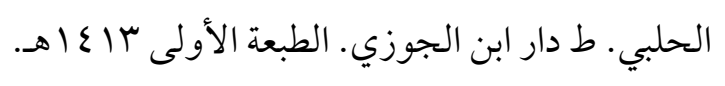

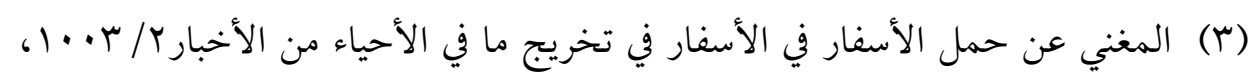

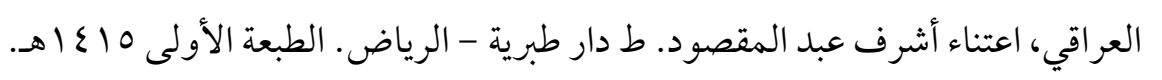


من أئمة الصنعة: هما حديثان بإسنادين •

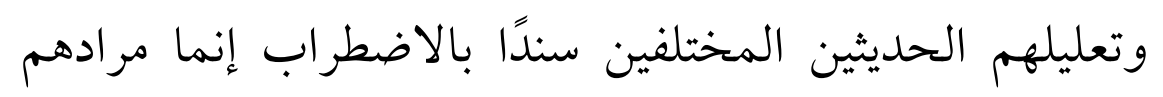

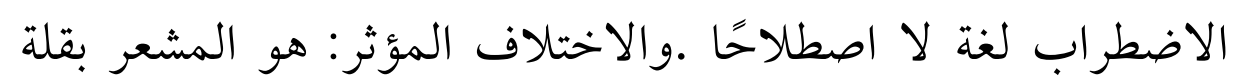

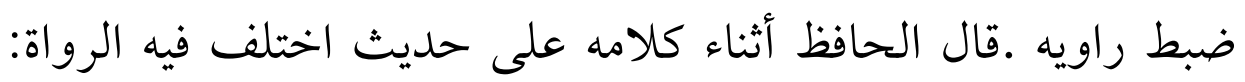
التلون في الحديث الواحد، بالإسناد الواحد، مع اتحاد المخرج يوهن إنهاء

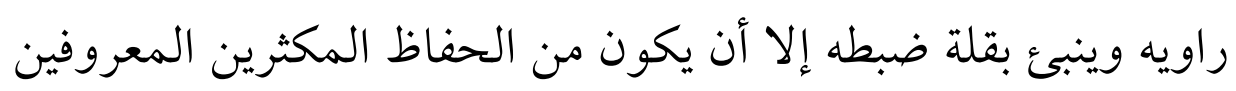
بجمع طرق الحديث، فلا يكون ذلك دالًا على قلة ضبطه(1). - الشروط التي يصير بها الحديث مضطربا:

$$
\begin{aligned}
& \text { 1 - - - مجود الاختلاف المؤثر. } \\
& \text { r } \\
& \text { r- أن تكون الأوجه متساوية. } \\
& \text { ع - أن لا يمكن الجمع. }
\end{aligned}
$$

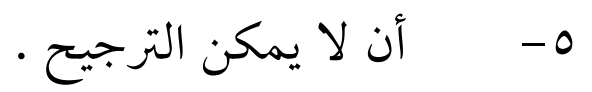

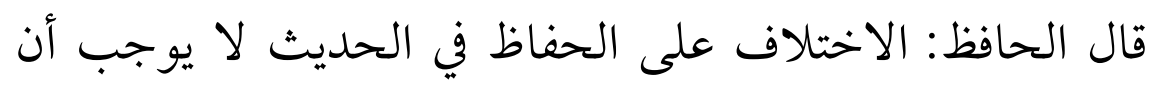

$$
\text { يكون مضطربًا إلا بشرطين: }
$$

أحدهما: استواء وجوه الاختلاف، فمتى رجح ألحرئ أحد الأقوال قدم

$$
\text { ولا يعل الصحيح بالمرجوح. }
$$

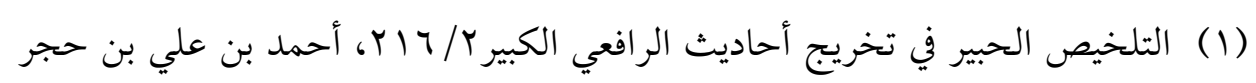

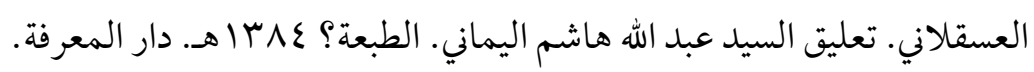




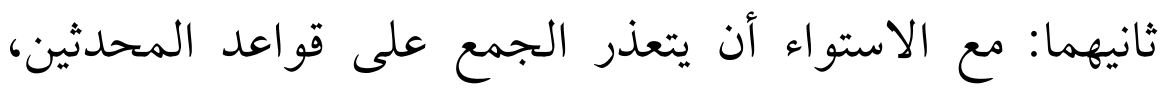

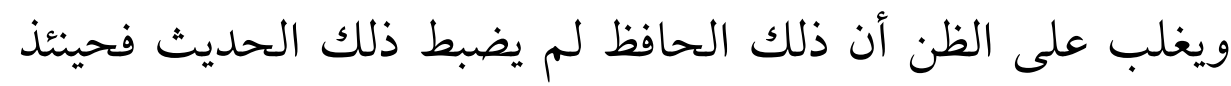

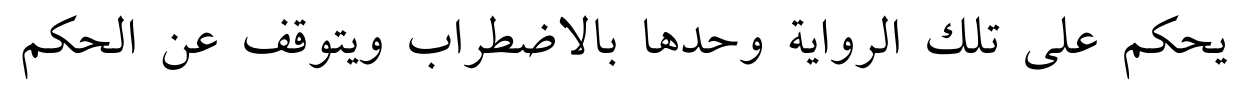
بصحة ذلك الحديث(1).

***

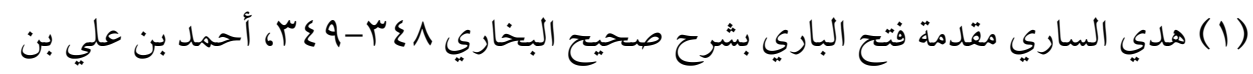
حجر العسقلاني. تحقيق: محب الدين الخطيب، وراجعه قصي محب الدين الخطيب.

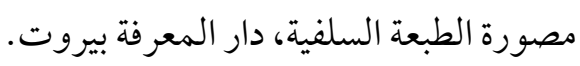




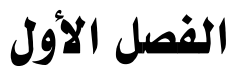

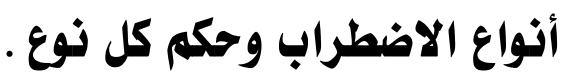

الاضطراب من حيث هو يرجع تارة إلى المتن وتارة إلى السند

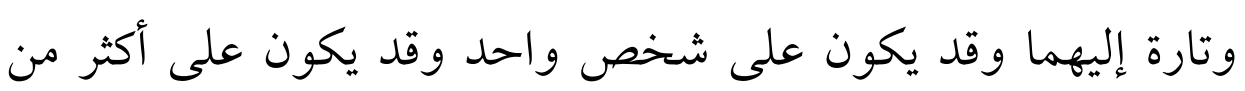

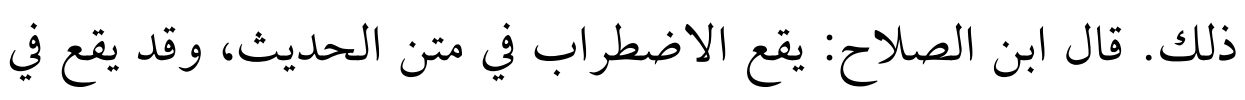

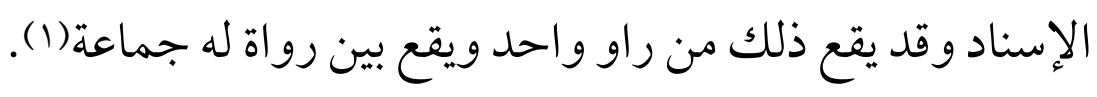

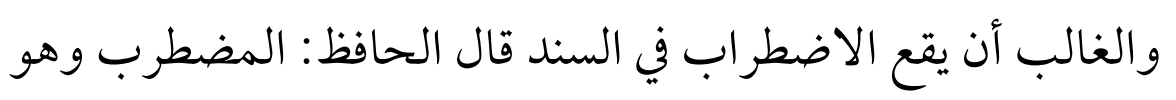

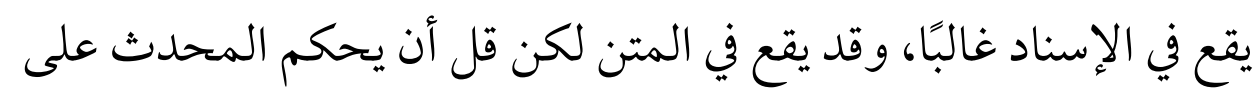

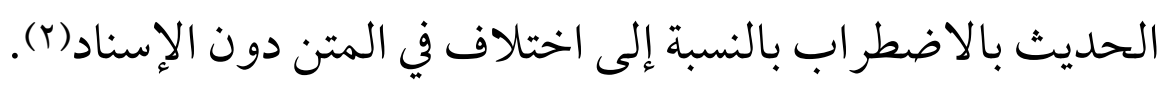

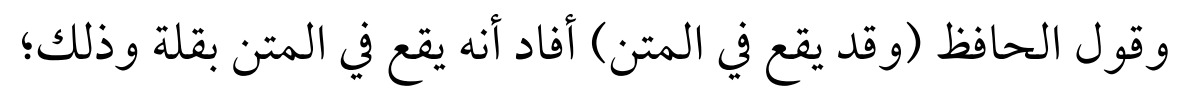

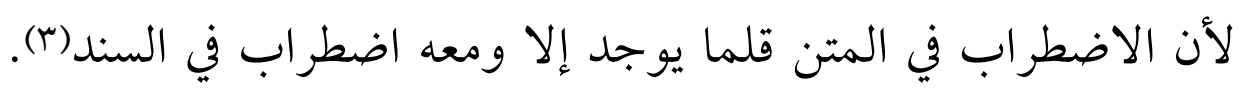

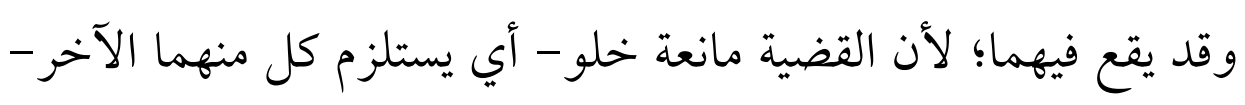
فيكون ذلك في المتن وفي السند معًا. ** *

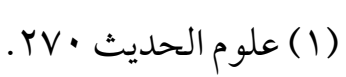

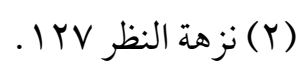

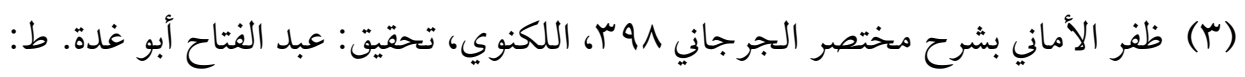

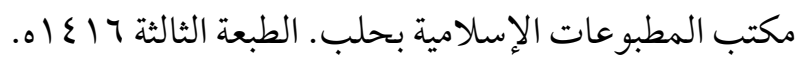




\section{المبحث الأول \\ مضطرب السند}

لأهل الحديث في الحديث المضطرب نظرتان: المطلب الأول: النظرة الأولى: من جهة الاضطراب: فالاضطراب وحده موجب لضعف الحديث ؛ لأنه دليل على عدم ضبط الراوي(1).

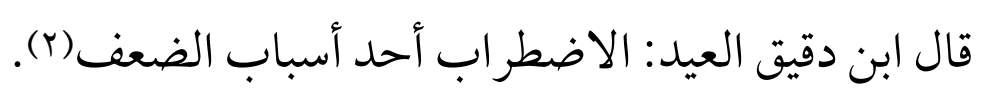
المطلب الثاني: النظرة الثانية: من جهة الراوي: فالر اوي إما أن يكون في مرتبة القبول أو الاعتبار أو الترك.

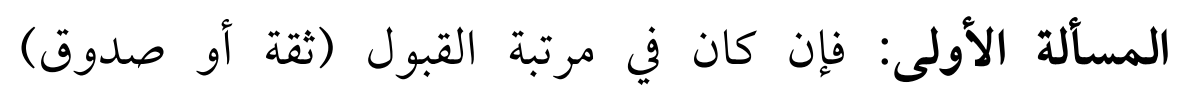
و اضطرب في الحديث ولم يضبطه، ضعف الحديث لعدم ضبطه لذلك الحديث بعينه، لا لضعفه.

قال العراقي في معرض ردّه على من ضعف راويًا ثقة لحديث رواه

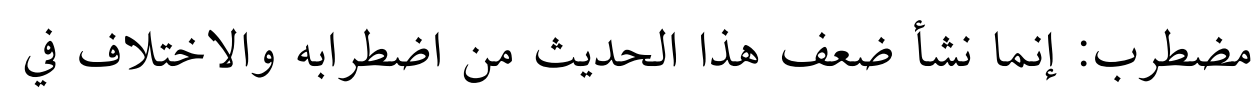
رفعه ووقفه ووصله وإرساله. واضطراب لفظه، لا من حال عبد الحميد

(1) التلخيص الحبير r/T/T)

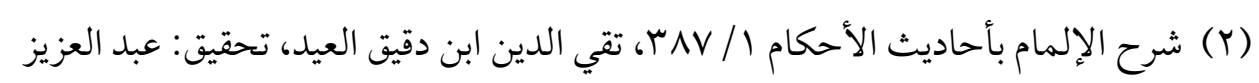

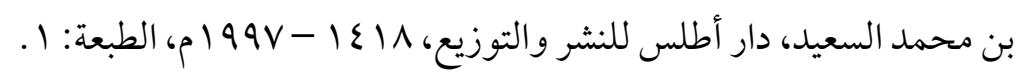


فقد وثقه النسائي و العجلي وابن حبان(1). المسألة الثانية: وإن كان الراوي في مرتبة الاعتبن واعبار (الضعيف

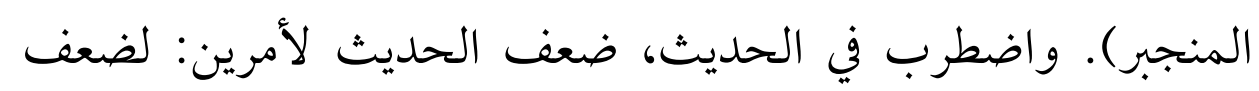
راويه. و ولاضطر ابه فيه.

قال ابن القطان في معرض بيانه لعلة حديث أعله بالاضطر اب: وذكر

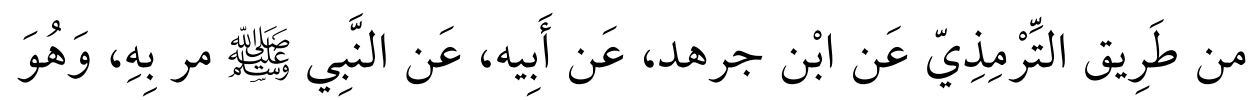

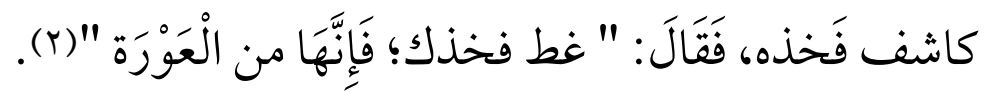

(1) ذيل ميزان الاعتدال / / بع| أبو الفضل عبد الرحيم بن الحسين زين الدين العراقي.

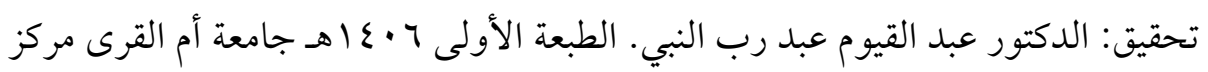

$$
\text { البحوث مكة المكرمة. }
$$

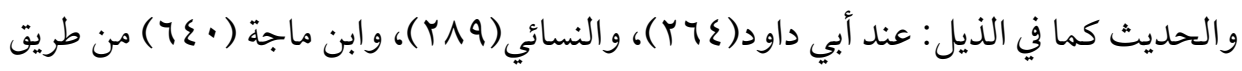

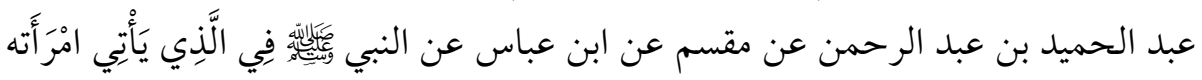

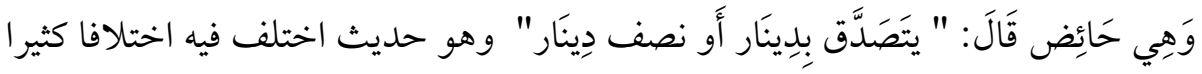

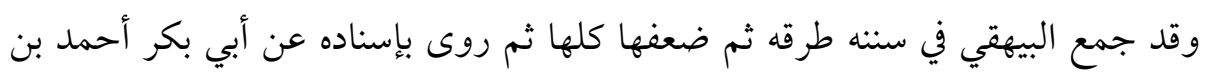

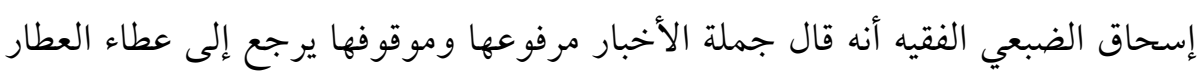

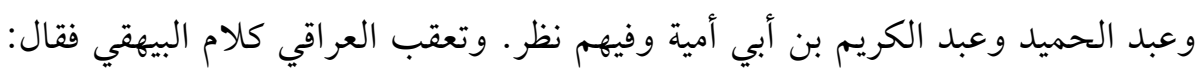

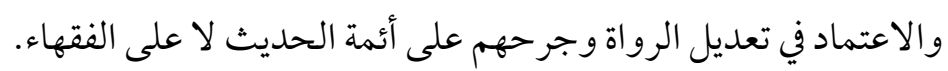

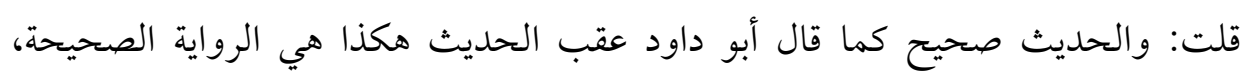

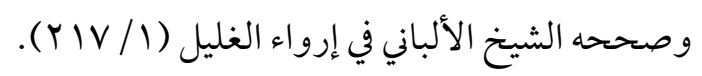

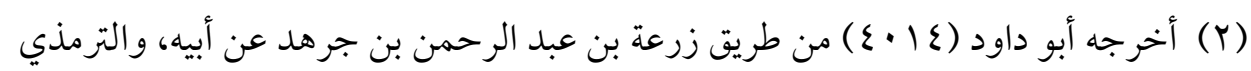
أرى (YV90)

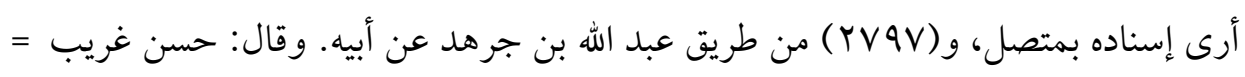




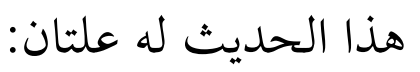
إحداهما: الاضطراب المورث لسقوط الثقة به وذلك أنهم يختلفون فيه)" ثم قال: (إذا كان الذي اضطراب الإض عليه بجميع هذا أو أو ببعضه أو بغيره غير ثقة أو غير معروف فالاضطراب هين حينئ يكون زيادة في وهنه وهذه حال هذا الخبر وهي العلة الثانية(1).

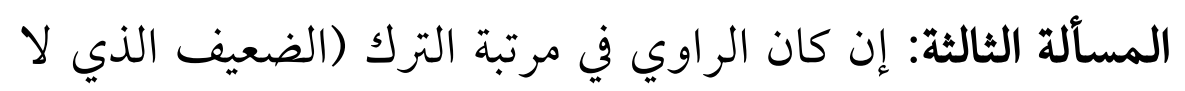
ينجبر) واضطرب في الحديث، ضعف الحديث ضعفًا شديدًا لأمرين:

$$
\text { لشدة ضعف راويه ولاضطر ابه فيه. }
$$

وإذا كان الاضطراب من الراوي الضعيف الذي لا ينجبر ضعفه ؛

$$
\text { فلا يتقوى حديثه؛ لأن ضعفه غير منجبر. }
$$

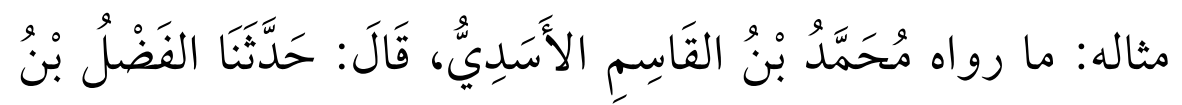

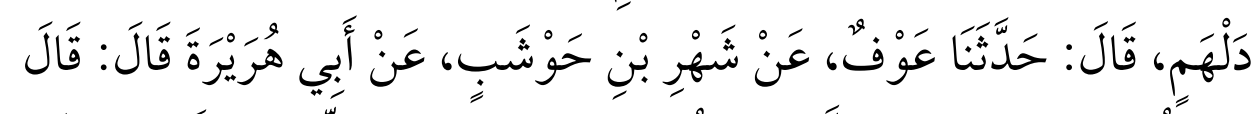

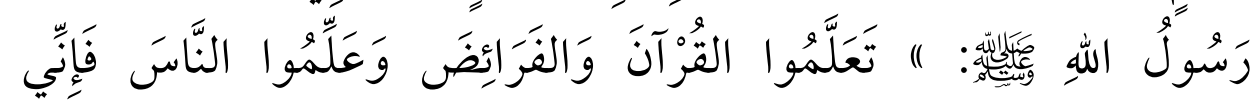

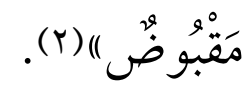

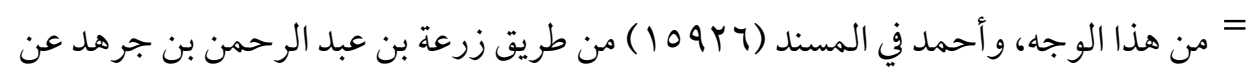

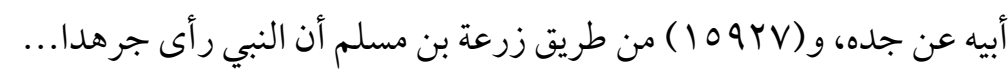

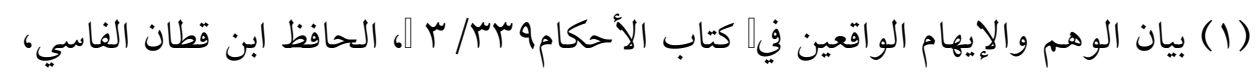

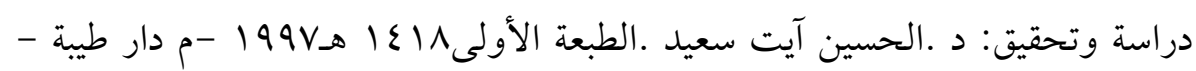

$$
\begin{aligned}
& \text { السعودية. } \\
& \text { (r) أخرجه الترمذي (Y) (Y) وقال: هذا حديث فيه اضطراب، وروى أبو أسامة هذا = } \\
& -199-
\end{aligned}
$$




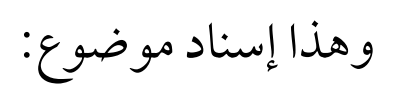

محمد بن القاسم كذبوه(1)، والفضل لين ورمئ ومدي بالاعتزال(r)،

$$
\text { وشهر صدوق كثير الإرسال والأوهام(r). }
$$

وخالفهم المثنى بن بكر فرواه عن عوف عن سليمان عن أبي

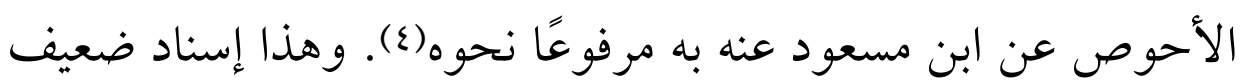

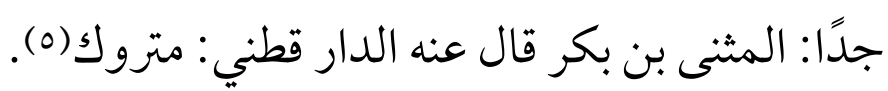

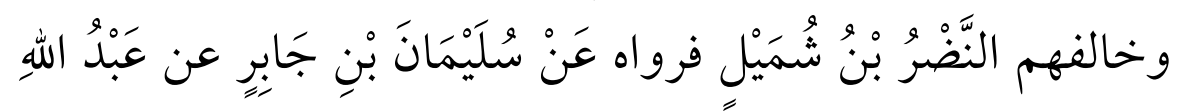

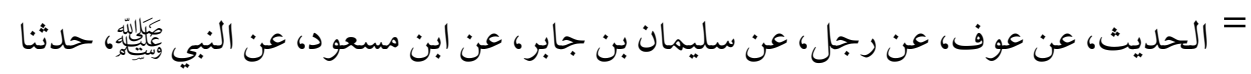

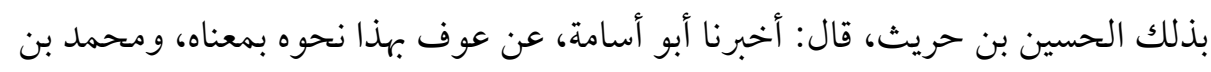

$$
\text { القاسم الأسدي قد ضعفه أحمد بن حنبل وغيره. }
$$

(1) تقريب التهذيب / / +0، ابن حجر العسقلاني. ط: دار الفكر، بيروت الطبعة الأولى

$$
\text { هـ }
$$

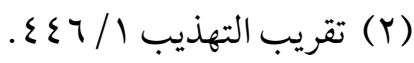

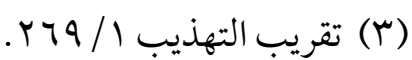

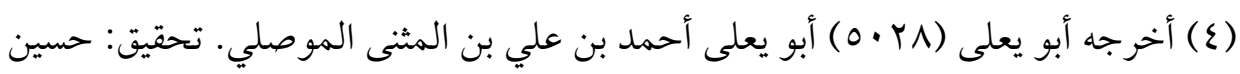

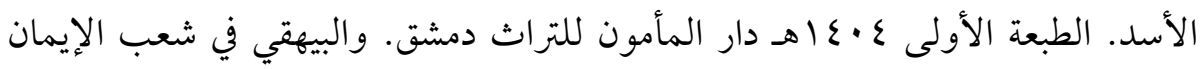

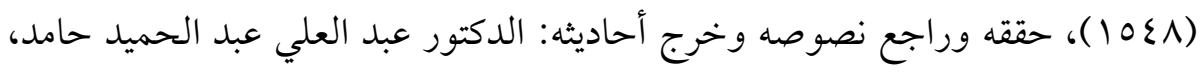

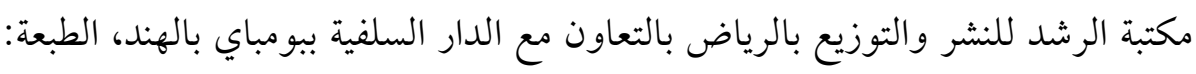

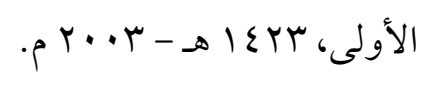

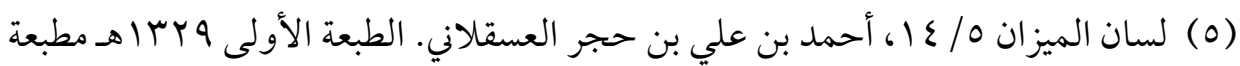

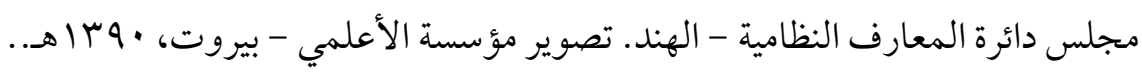


ابْنِ مَسْعُودٍ عنه به مرفوعًا نحوه(1). وهذا إسناد ضعيف: سُلَيْمَانَ بْنِ جَابرٍ مجهول(r).

ولرواية أبي هريرة متابعة من طريق حَفْصُ بْنُ عُمَرَ بْنِ أَبِي الْعِطَافِ

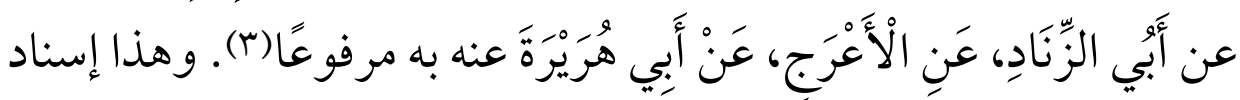

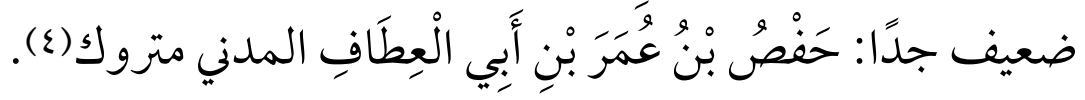

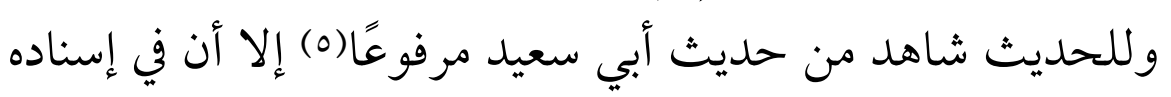
الْمُسَيَّبِ بْنِ شَرِيكٍ الكوفي وهو متروك (7) . وعليه يبقى الحديث ضعيفًا

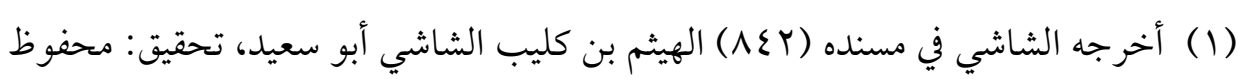

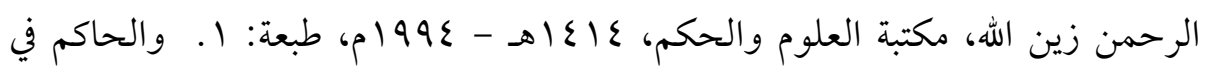

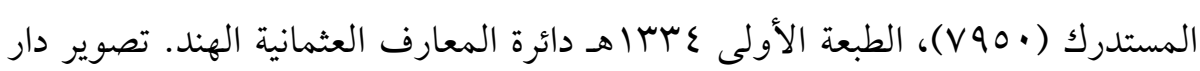

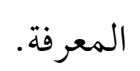

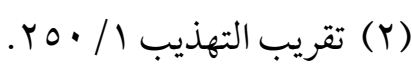

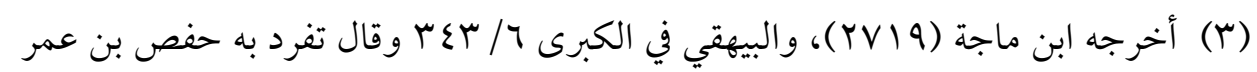

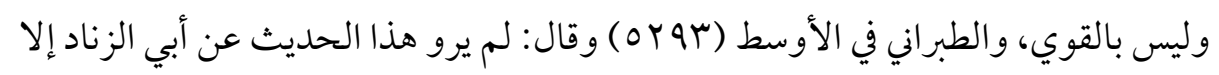

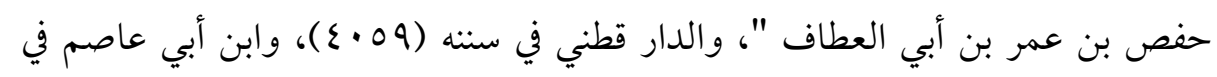

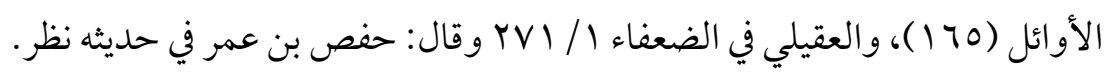

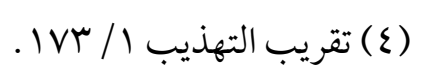

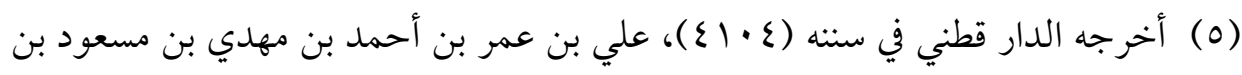

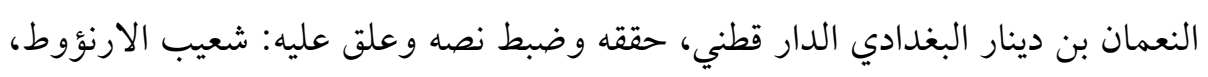

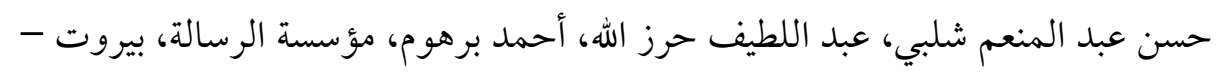

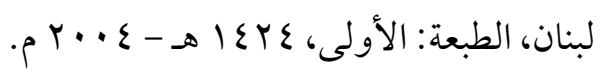

$$
\begin{aligned}
& \text { (7) لسان الميزان ج/ 1 بـ. }
\end{aligned}
$$




\section{لا يتقوى، وضعفه ابن كثير في التفسير (1).

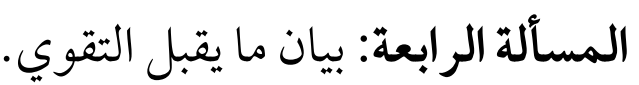

الاضطراب من أسباب ضعف الحديث وهذا الضعف ليس شديلًا بل هو من الضعف المنجبر. قال الأثرم: قلت لأبي عبد الله أبو معشر المدني يكتب حديثه ؟ فقال: عندي حديثه مضطرب لاب لا يقيم الإسناد ولكن اكتب حديثه اعتبر به(r).

قال الحافظ بعد ذكره حديثًا مضطربًا صححه الحاكم: "(في تصحيحه نظر ؛ لأن في أبي أيوب الإفريقي - واسمه عبد الله بن علي مقالًا مع الاضطر اب من عاصم في سنده وتكلمو إني حفظه. وإنما قلت: حسن ؛ لاعتضاده بما قبله (r).

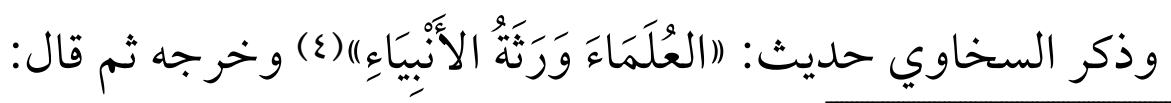

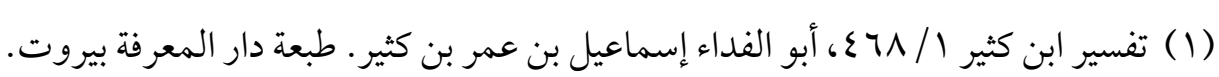

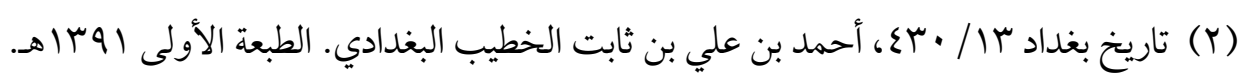
مكتبة الخانجي - القاهرة.

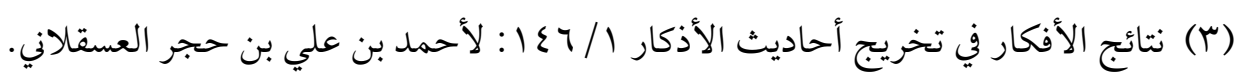

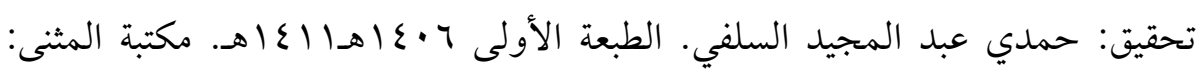
بغداد، ومكتبة ابن تيمية: القاهرة.

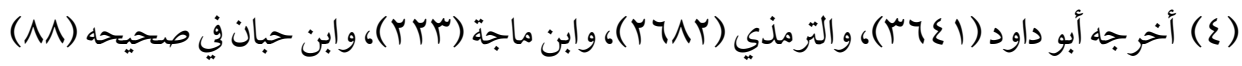

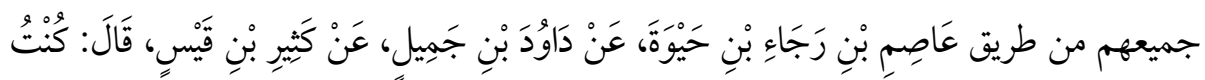

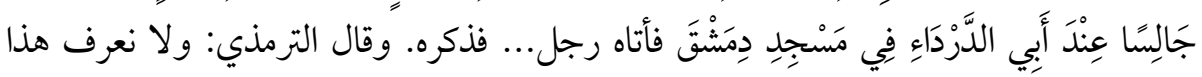

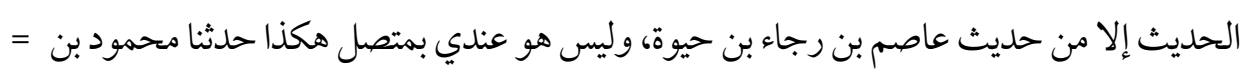


صححه ابن حبان والحاكم وغيرهما وحسنه حمزة الكناني وضعفه

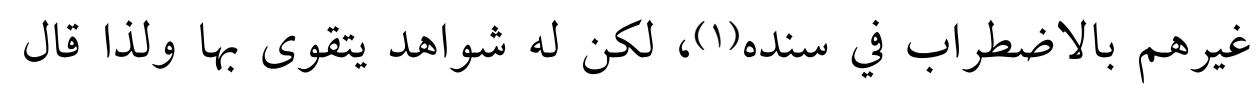
شيخنا له طرق يعرف بها أن للحديث أصلاً (r).

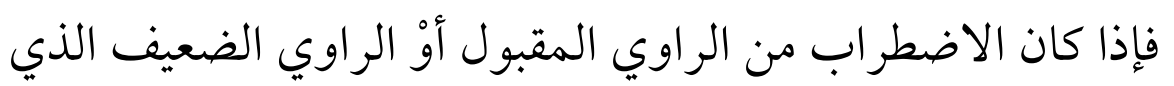

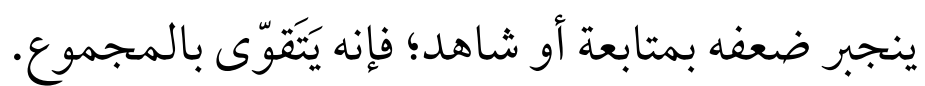

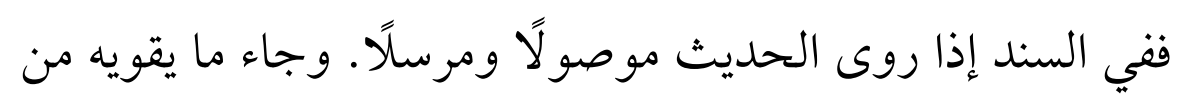
متابعة أو شاهد معتبر تقوى به.

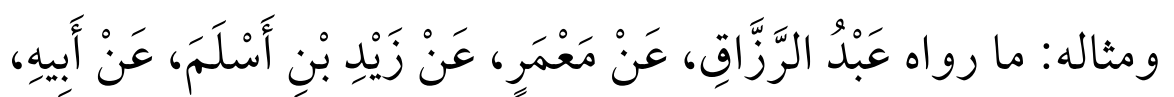

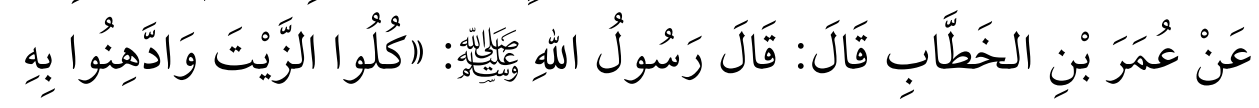

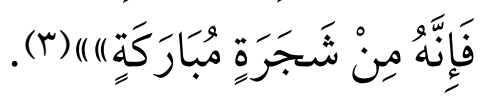

= خداش بهذا الإسناد وإنما يروى هذا الحديث عن عاصم بن رجاء بن حيوة، عن الوليد بن جميل،

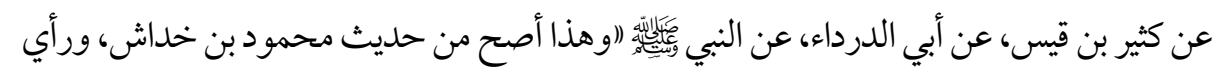

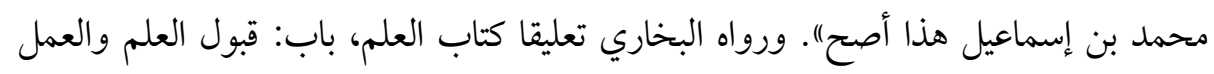

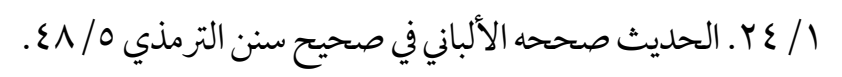

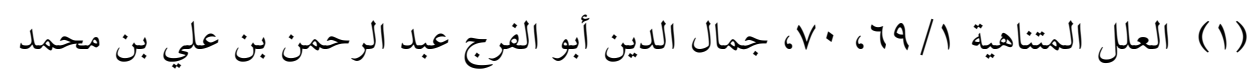

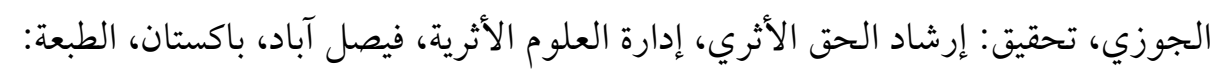

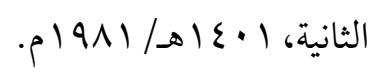

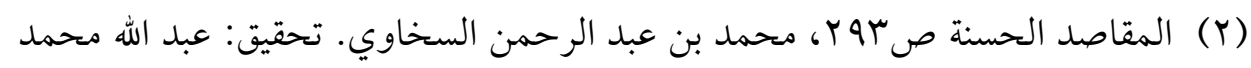

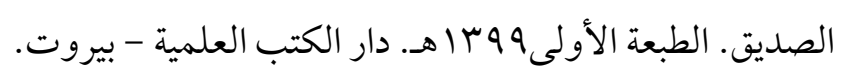

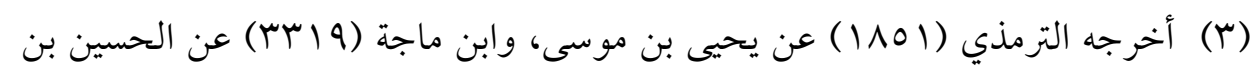

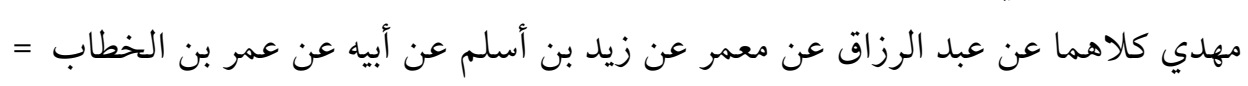


رواه عبد الرزاق أيضًا عن معمر عن زيد بن أسلم عن أبيه مرفوعًا

مرسلًا.

فاضطرب فيه عبد الرزاق مرة يصله ومرة يرسله. وأعله الترمذي

$$
\text { بالاضطراب(1). }
$$

تابعه زياد بن سعد عن زيد بن بن أسلم عن أبيه عن عمر مرفوعًا نحوه (r)

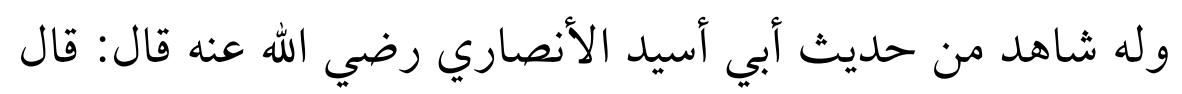

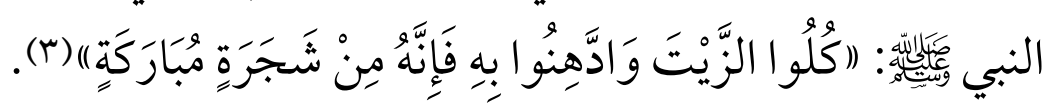
وقد يكون للسند شاهد ولا يتقوى به كحديث عبد الله بن عمرو الله

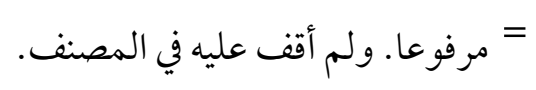

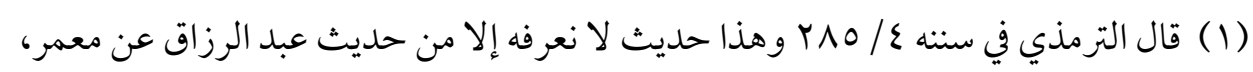

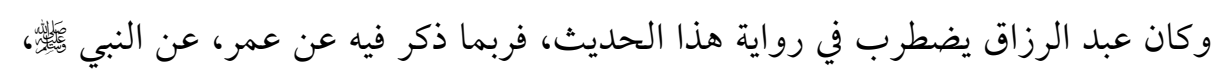

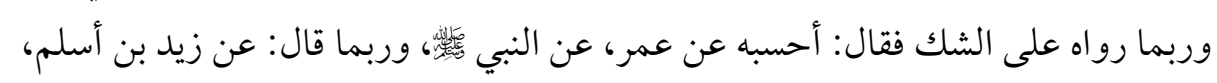

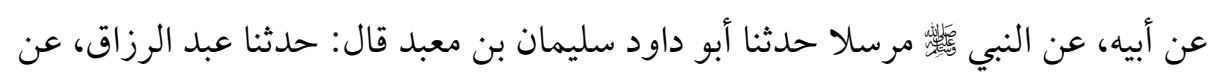

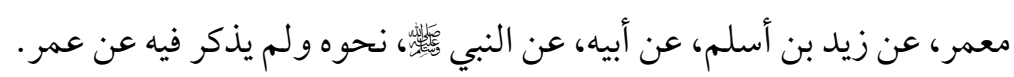

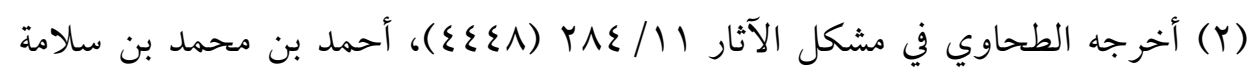

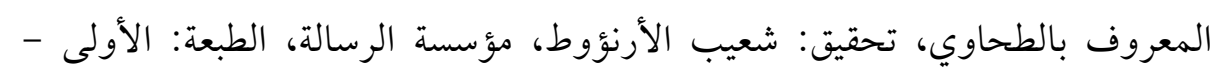

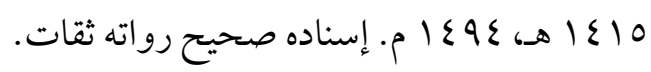

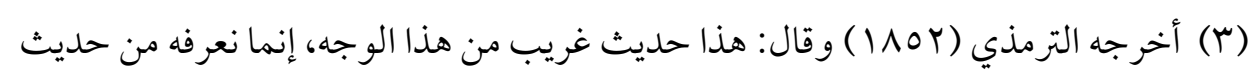

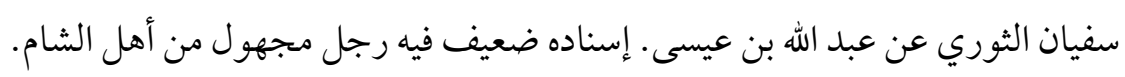




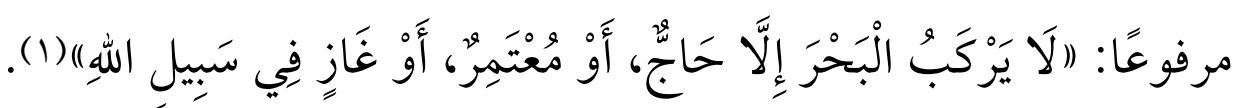

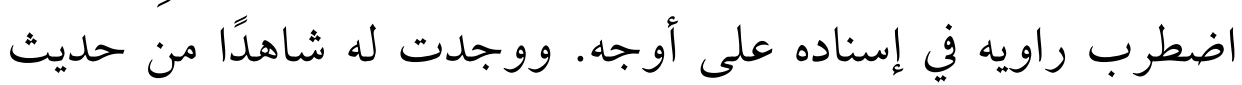

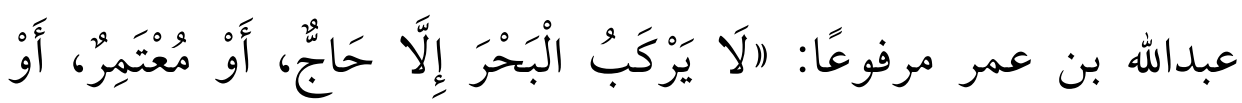

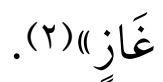

فهذا لا يتقوى الحديث به ؛ لاحتمال أن يكون موقوفًا وهو مما للر أي فيه مجال أو مقطوعًا من قول التابعي فلا يتقوى بهما. ***

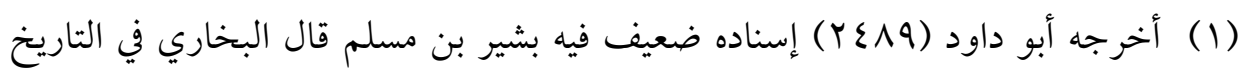

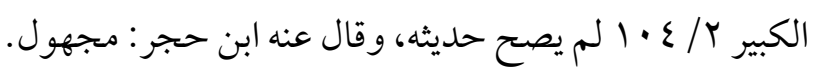

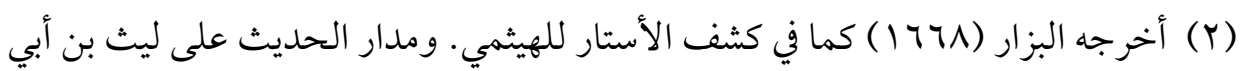

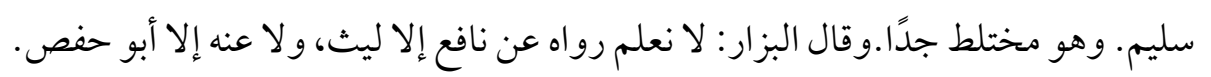




\section{المبحث الثاذي}

\section{مضطرب المتنز}

والاضطراب في المتن إذا جاء الحديث بألفاظ مضطربة. وجاء ما يقوي بعض هذه الألفاظ تقوى به.

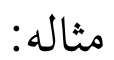

قال الترمذي: حدثنا مُحَمَّدُ بْنُ إِنْمَاعِيلَ الوَاسِطِيُّ، قَالَ: سَمِعْتُ

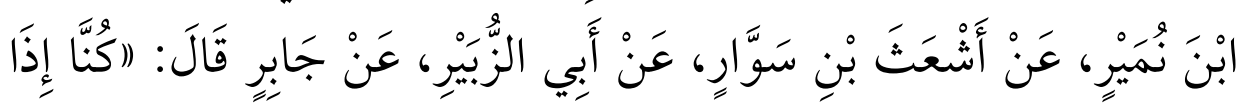

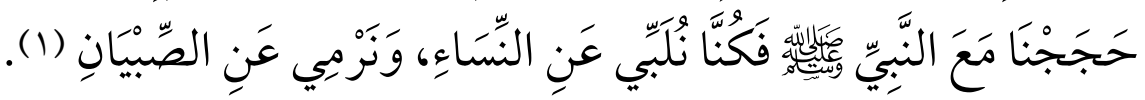
وهذا إسناد ضعيف:

$$
\text { فيه أشعث بن سوار ضعيف(r). }
$$

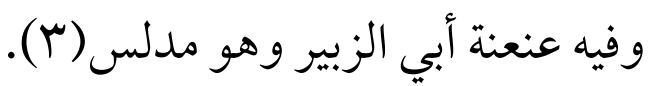
وأعل باضطر اب متنه.

فرواه ابن أبي شيبة عن ابن نمير عن أشعث عن أبي الزبير عن جابر

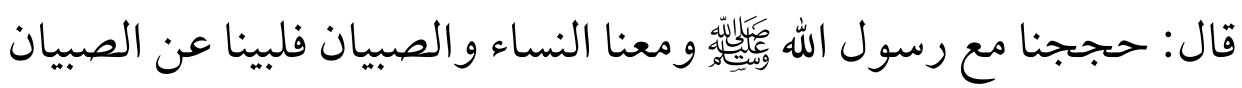

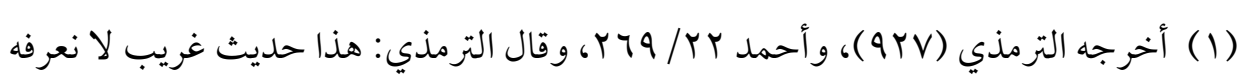

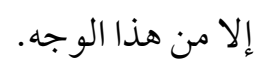

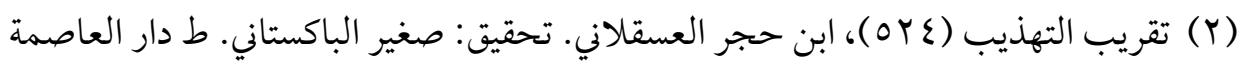

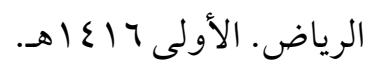

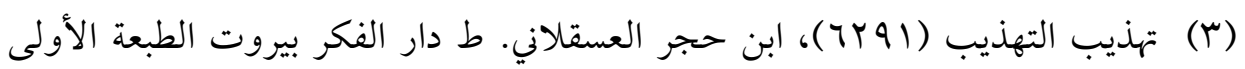




$$
\text { ورمينا عنهم)|(1). }
$$

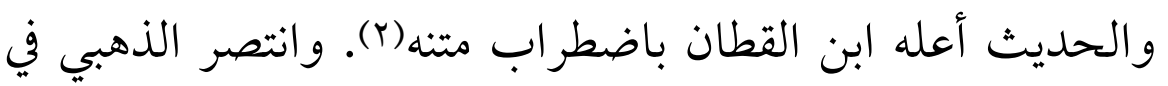

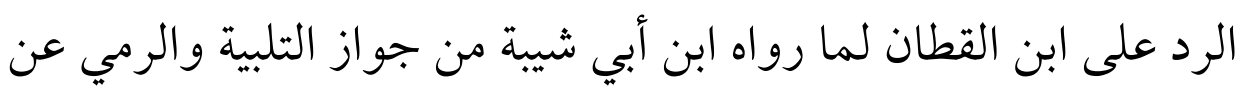

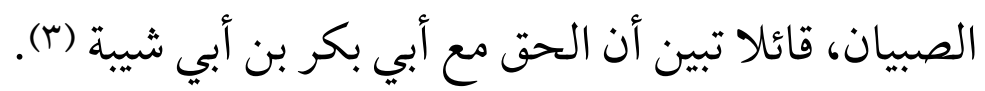
* *

(1) أخرجه ابن أبي شيبة (1) \& \& ) )، أبو بكر عبد الله بن محمد بن إبر اهيم بن عثمان العبسي.

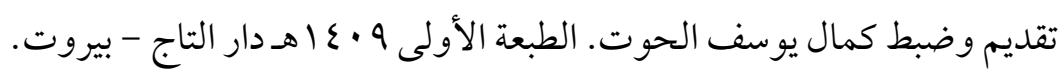

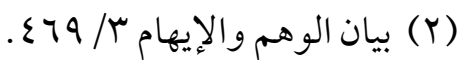

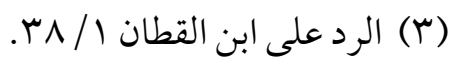




\section{المبحث الثالث:}

\section{مضطرب السنلد والمتنز}

يقع الاضطر اب أيضا في السند والمتن معا مما يكون سببا في ضعف

$$
\text { الحديث وعدم الاعتماد عليه. }
$$

$$
\text { ومثال مضطرب السند و المتن: }
$$

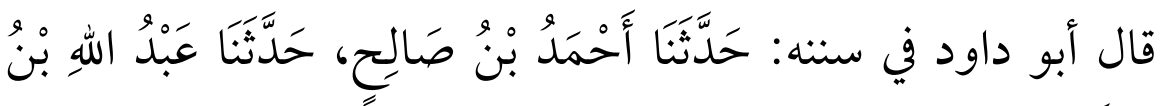

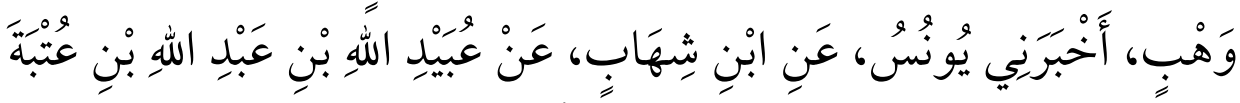

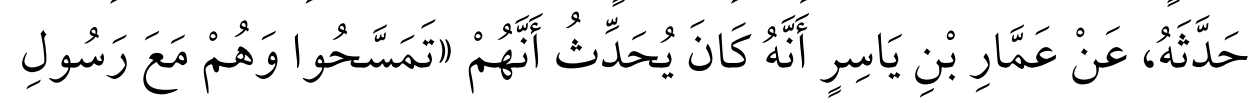

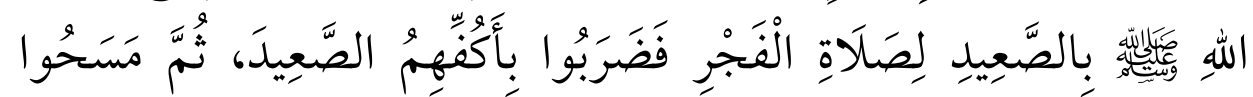

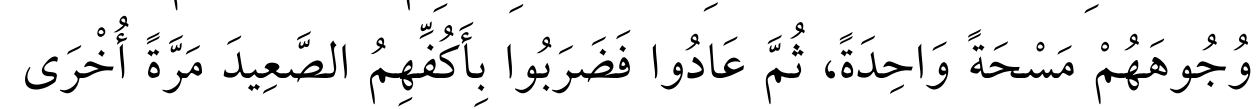

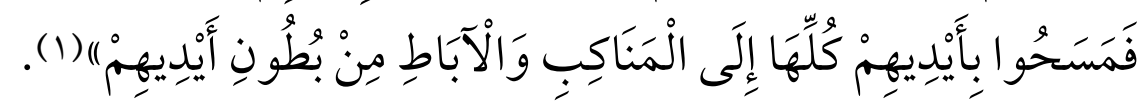

$$
\text { وهذا إسناد ضعيف لأمرين: }
$$

$$
\text { r - الانقطاع بين عبيد الله وعمّار (r). }
$$

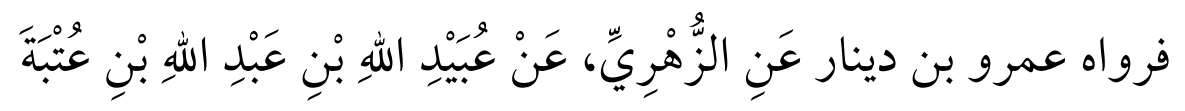

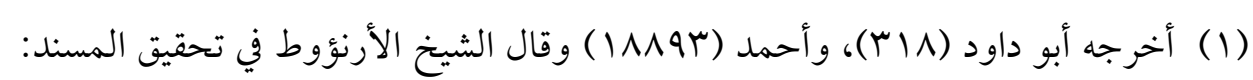

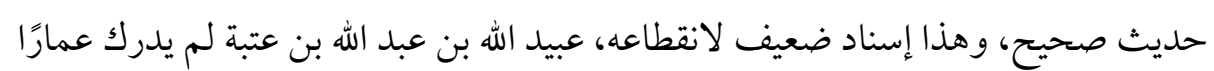

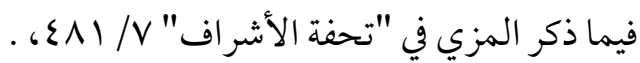

$$
\begin{aligned}
& \text { (Y) نصب الراية / / } 100 \text { للزيلعي. }
\end{aligned}
$$




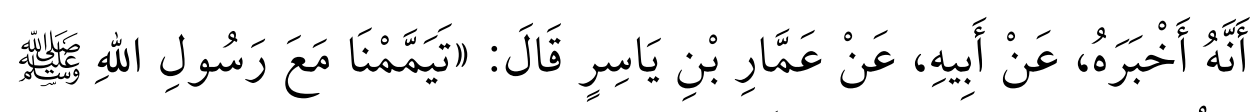

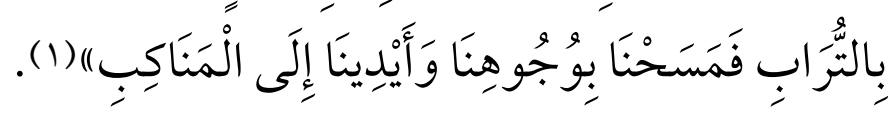

$$
\text { فهنا قال (عن أبيه) وفي الأول لم يقل. }
$$

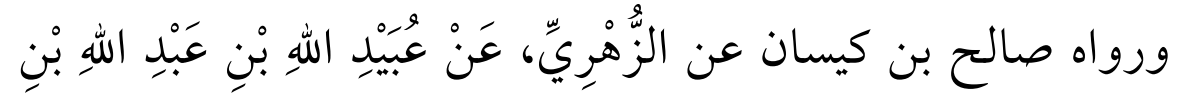

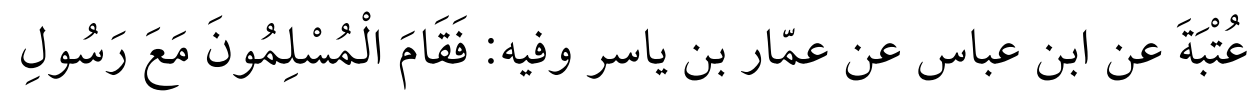

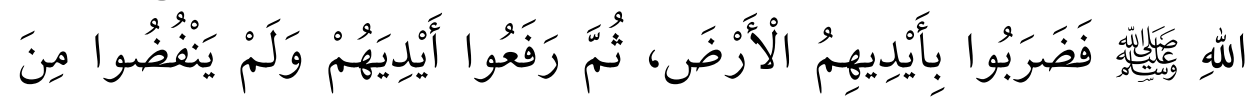

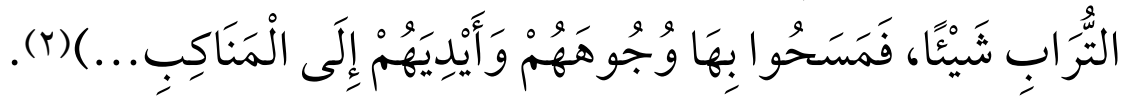

$$
\begin{aligned}
& \text { فهنا جعلها ضربة واحدة. وفيما سبق ضربتين. }
\end{aligned}
$$

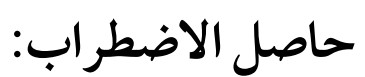

$$
\text { وقع الاضطر اب في سنده وفي متنه: }
$$

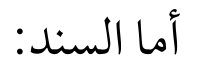

1 - الزهري عن عبيد الله بن عبد الله بن عتبة عن عمّار (r).

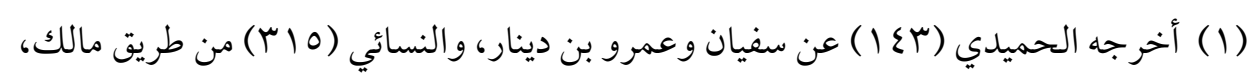

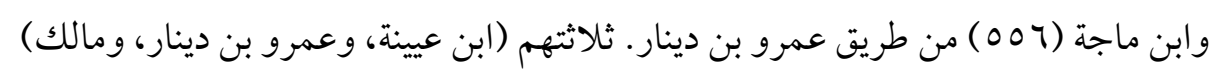

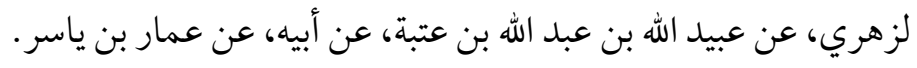

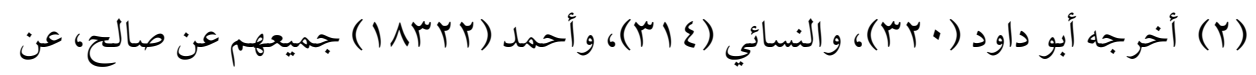

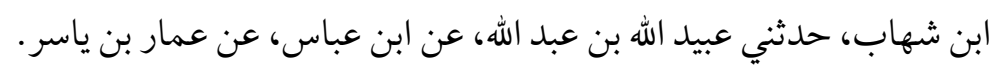

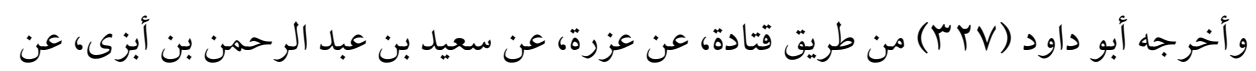

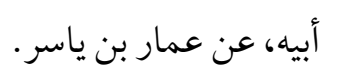
(r) قال الذهبي في السير ع / عVOع روايته عن عمار مرسلة. 
r - الزهري عن عبيد الله بن عبد الله عن أبيه عن عمّار.

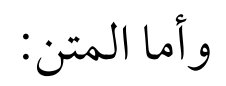
فمرة يقول: ضربة. ومرة يقول: ضربتين .فهذا اضطراب في سنده ومتنه.

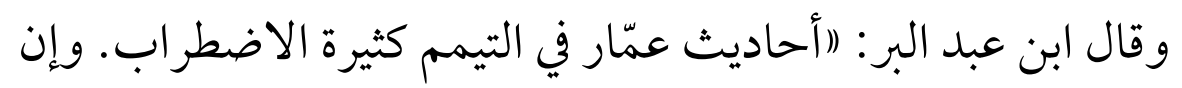

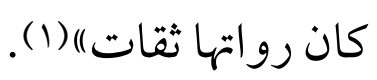
** *

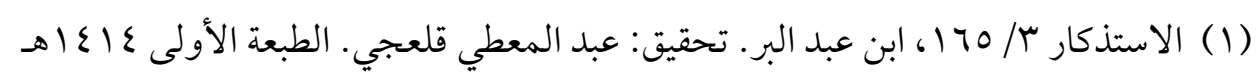

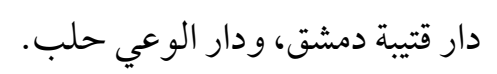




\section{الفصل الثاذي: - الثي}

\section{آراء العلماء في الاختلاف على الراوي .}

الاختلاف: هو أن يروي الرواة الحديث فيختلفون فيه، فيرويه

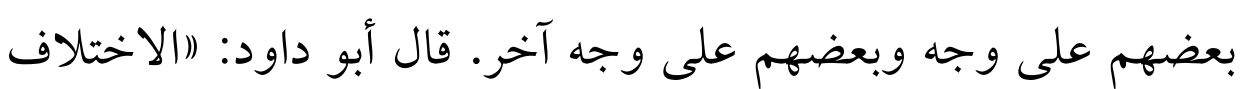
عندنا: ما تفرد قوم على شيء، وقو وقوم على شيء)|(1).

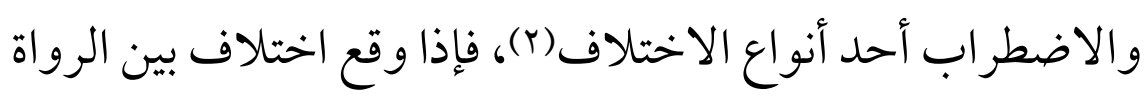
فللعلماء في هذا الاختلاف ثلاثة مذاهب:

\section{المبحث الأول:}

\section{الملهب الأول : الاختلاف يؤثر مطلقًا إلا إن دل دليل .}

يرى أصحاب هذا المذهب أن الاختلاف يقدح في الحديث إلا إنْ دَلَّ دليل على أنه عند المختلف عليه بالطريقين وإليه ذهب كثير من أهل الحديث(r). قال الحافظ: (اشرط الاضطراب أن تتساوى الوجوه في

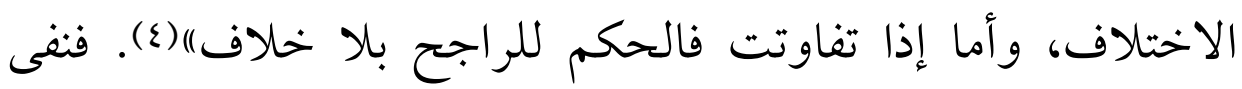

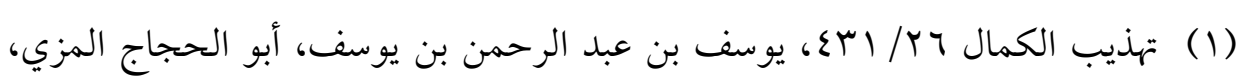

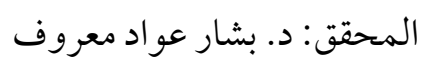

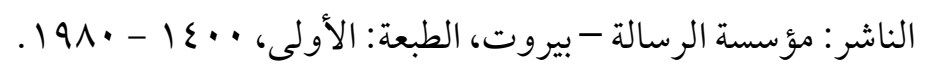

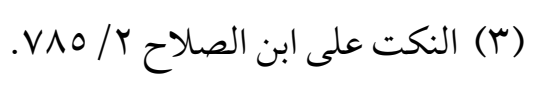

الإصابة • 197/1، ابن حجر العسقلاني. تحقيق محمد علي البجاوي، تصوير دار 
وجود الخلاف والله أعلم. وحجتهم:

أن الاختلاف على الراوي دليل على عدم ضبطه في الجملة، فيضر

ذلك ولو كان رواته ثقات إلا أن يقوم دليل على أنه عند الريل على على صاوي

المختلف عليه عنهما جميعًا أو بالطريقين (1).

**

(1) الاقتراح في بيان الاصطلاح (rrYr) لابن دقيق العيد، تحقيق عامر صبري، دار البشائر -

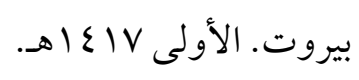




\section{المبجث الثاذي}

\section{الملذهب الثاني: الاختلاف في السند لا يؤثر وقد يؤثر في المتن}

يرى أصحاب هذا المذهب أن الاختلاف بين الرواة المقبولين (ثقة

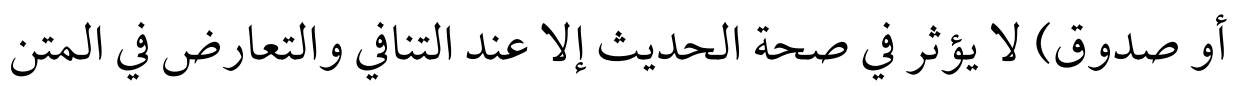
دون السند.

و إليه ذهب الفقهاء وأكثر الأصوليين وطائفة من المحدثين(1). قال الحافظ أبو يعلى الخليلي في معرض بيانه للعلة: (أن يروي

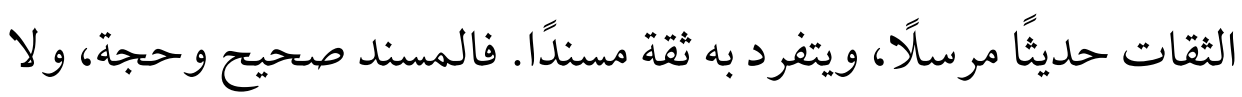
تضره علة الإرسال)|(r)، والاضطراب المؤثر في السند إذا كان راويه

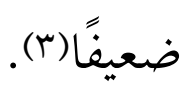

حجتهم: أن العمدة في تصحيح الحديث عدالة الراوي وجزمه

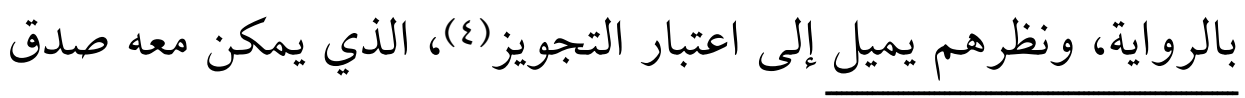
(1) البحر المحيط في أصول الفقه ع/بوبr، الزركشي، تحقيق: عمر بن سليمان الأشقر

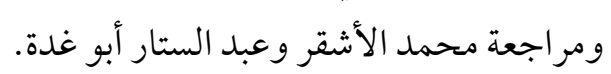

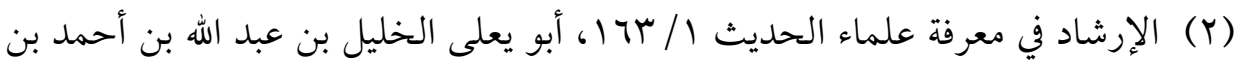

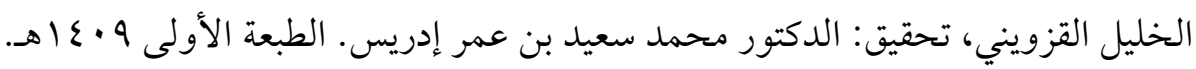

$$
\begin{aligned}
& \text { مكتبة الرشد - الرياض. }
\end{aligned}
$$

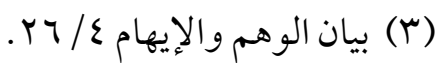

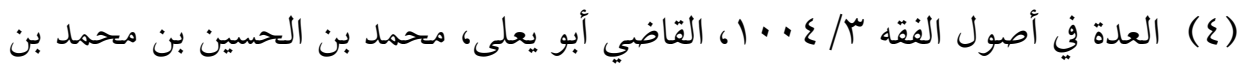

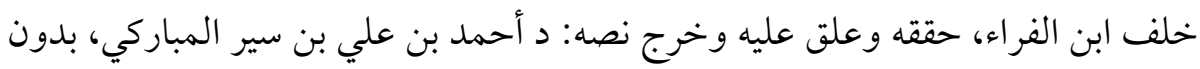

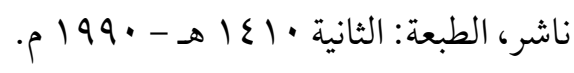


الراوي وعدم غلطه فمتى حصل ذلك وجاز أن لا يكون غلطًا، وأمكن

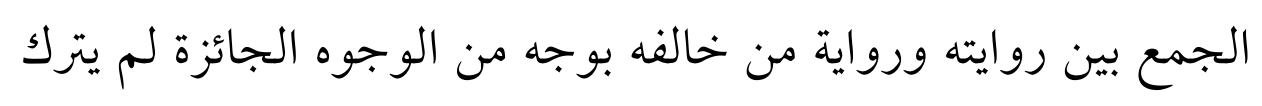
حديثه (1).

وأن توهيم حافظ في زيادة زادها لا معنى له إلا لو صرح الناس

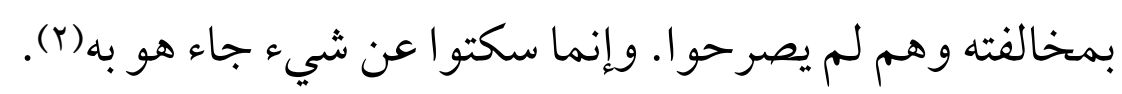

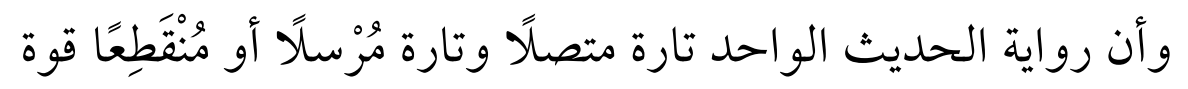

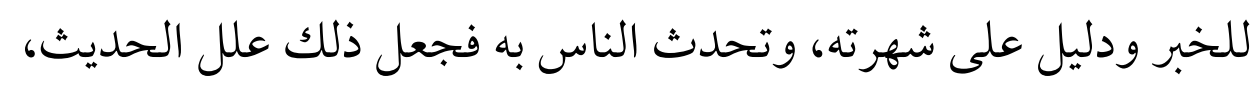
شيء لا معنى له (r). وقال أبو الحسن بن الحصار الأندلسي: (إن للمحدثين أغراضًا في

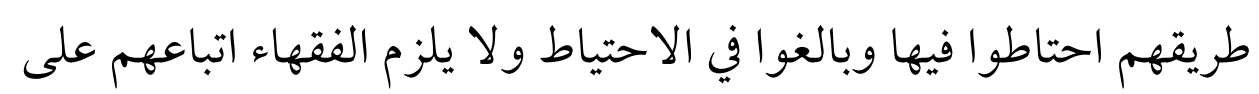

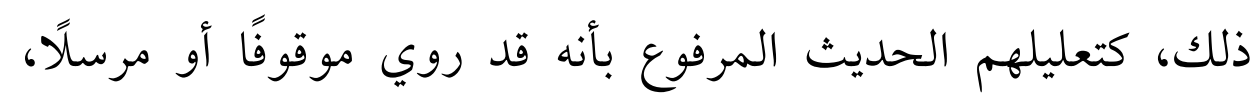

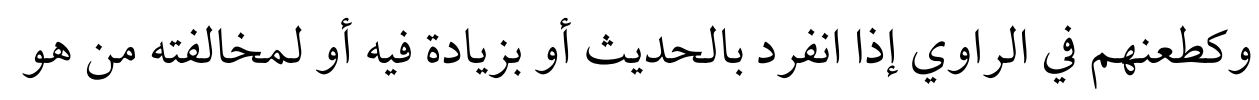

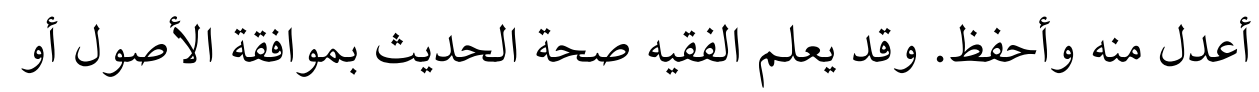

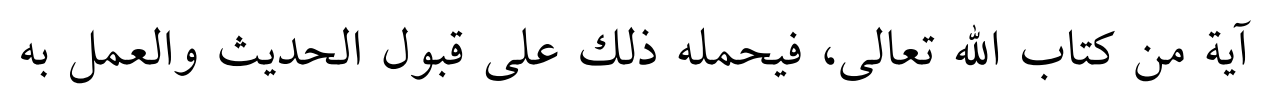

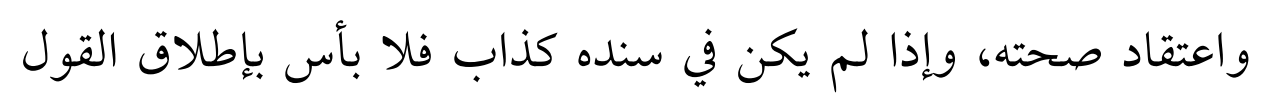

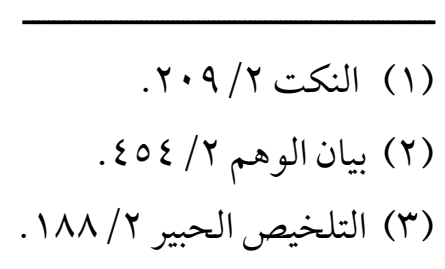


بصحته إذاو وافق كتاب الله تعالى وسائر أصول الشريعة)(1). وقال ابن القطان الفاسِي: (الا نرى الاضطر اب في الإسناد علة؛ فإنما

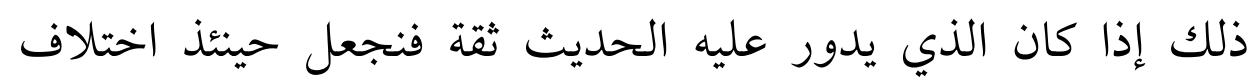

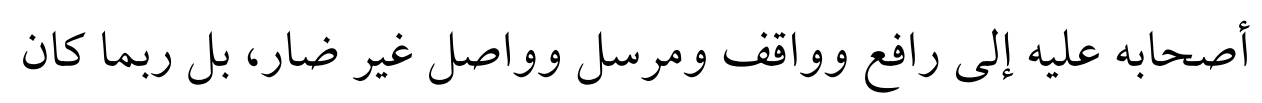

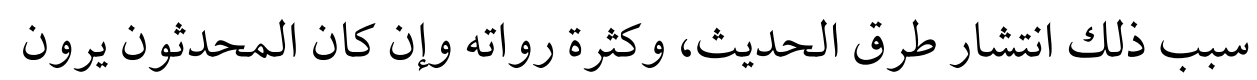
ذلك علة تسقط الثقة بالحديث المروي بالإسناد المضطرب فيه)(r).

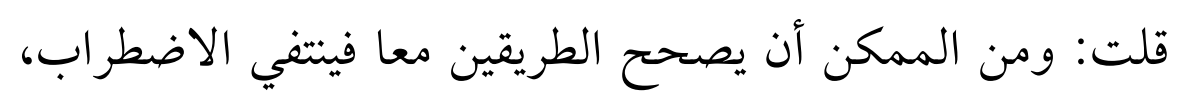

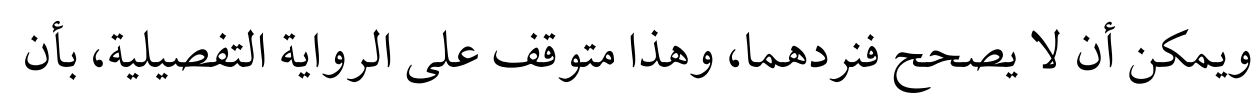
تدرس كل رواية على حالها والحكم عليها بما يليق بحالها. ***

(1) النكت / / ا • 1، لأبي عبد الله محمد الزركشي، تحقيق: زين العابدين بن محمد رسالة

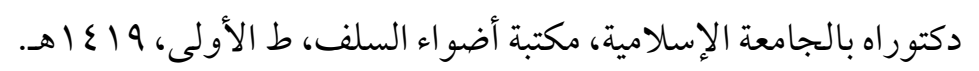

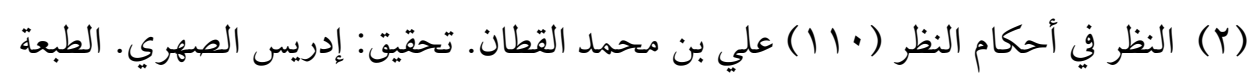
الأولى 7 اع اهـ. دار حياء التراث - بيروت. دار الثقافة - الدار البيضاء.. 


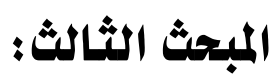

\section{الملذهب الثالث: ليس كل اختلافِ مؤثرًا}

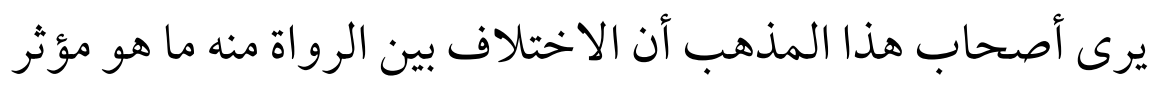

$$
\text { في ثبوت الحديث و منه ما ليس بمؤثر في ثبوت الحديث. و إليه ذهب }
$$

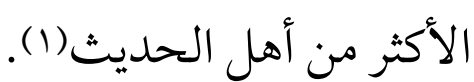

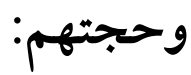

أن الحديث الواحد تحكمه ملابسات ومداخلات لا تتوفر في كل حديث إذ ليست الرواة الثقات في درجة واحدة ولا أحوال الرواة منضبطة، فالوهم و الغلط يطر أ على الثقات فما دونهم. قال الحازمي: (الرواية يراعى فيها الألفاظ والأحوال والأسباب لتطرق الوهم إليها والتغيير والتبديل ويختلف ذلك بالكبر والصغر فروايه

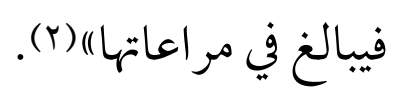

فإذا كان ذلك كذلك فلا تطرد القاعدة بل يحكم لكل حديث خاص

$$
\text { بحكم خاص. }
$$

وأن القرائن و الدلالات معمول بها في هذا العلم ؛ إذ هو مبني على غلبة الظن، فإن غلب على الظن بالقرائن أن الراوي ضبط ما تحمله وله

$$
\text { VVA/r (1) النكت (Y) }
$$

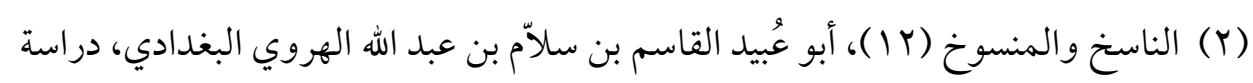

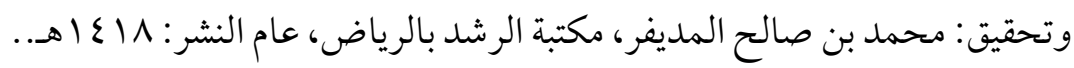

